\title{
Uncertainty quantification and sensitivity analysis of volcanic columns models: Results from the integral model PLUME-MoM
}

\author{
M. de' Michieli Vitturi ${ }^{1}$, S. L. Engwell ${ }^{1,2}$, A. Neri ${ }^{1}$, S. Barsotti ${ }^{3}$,
}

\begin{abstract}
The behaviour of plumes associated with explosive volcanic eruptions is complex and dependent on eruptive source parameters (e.g. exit velocity, gas fraction, temperature and grain-size distribution). It is also well known that the atmospheric environment interacts with volcanic plumes produced by explosive eruptions in a number of ways. The wind field can bend the plume but also affect atmospheric air entrainment into the column, enhancing its buoyancy and in some cases, preventing column collapse. In recent years, several numerical simulation tools and observational systems have investigated the action of eruption parameters and wind field on volcanic column height and column trajectory, revealing an important influence of these variables on plume behavior. In this study, we assess these dependencies using the integral model PLUME-MoM, whereby the continuous polydispersity of pyroclastic particles is described using a quadrature-based moment method, an innovative approach in volcanology well-suited for the description of the multiphase nature of magmatic mixtures. Application of formalized uncertainty quantification and sensitivity analysis techniques enables statistical exploration of the model, providing information on the extent to which uncertainty in the input or model parameters propagates to model output uncertainty. In particular, in the framework of the IAVCEI Commission on tephra hazard modeling inter-comparison study, PLUME-MoM is used to investigate the parameters exerting a major control on plume height, applying it to a weak
\end{abstract}

Email address: mattia.demichielivitturi@ingv.it (M. de' Michieli Vitturi)

${ }^{1}$ Istituto Nazionale di Geofisica e Vulcanologia, Sezione di Pisa, Pisa, Italy

${ }^{2}$ Now at: British Geological Survey, Edinburgh, United Kingdom

${ }^{3}$ Vedurstofa Íslands, Icelandic Met Office, Reykjavík, Iceland 
plume scenario based on 26 January 2011 Shinmoe-dake eruptive conditions and a strong plume scenario based on the climatic phase of the 15 June 1991 Pinatubo eruption.

Keywords:

volcanic column, numerical model, sensitivity analysis, uncertainty quantification, entrainment, column height

1. Introduction

A key role of column models is to define appropriate input parameters for ash dispersal models, for example mass flow rate, particle grain size and height of dispersion. Consequently such models are critical for hazard and risk analysis for explosive eruptions, and particularly the injection of volcanic gas and ash into the atmosphere (e.g. Barsotti et al., 2010; Durant et al., 2010; Wilson et al., 2014). The behaviour of plumes associated with explosive volcanic eruptions is complex (Sparks et al., 1997), and is dependent on both source flow conditions (e.g. exit velocity and temperature) and environmental characteristics (e.g. wind, atmospheric temperature, density and pressure profiles). Currently, it is impossible for a numerical model to capture all of the intricacies of these dependencies and therefore numerical models paint a simplified picture of the processes. As a consequence, proper understanding of model limitations associated with these simplifications is required for useful model application and interpretation of results.

All numerical models require the identification of an appropriate range of input parameters. While some plume model input parameters (e.g. vent radius) may be inferred from direct observation of an event, or from knowledge of previous events, other inputs are less tangible, for example those associated with entrainment (Kaminski et al., 2005). In addition, all inputs are associated with a degree of uncertainty, and the extent to which this uncertainty propagates to model output uncertainty depends on the interaction of variables within the model.

Application of formalized uncertainty quantification and sensitivity analysis techniques (Iman and Helton, 1988; Saltelli et al., 2010) enables statistical exploration of the model, providing information on the relation between model input and output, and reduction of model uncertainty, by identifying those inputs that result in significant variation in model output and therefore may require targeted research. 
Here, we demonstrate the application of uncertainty quantification and sensitivity analysis using the integral volcanic plume model PLUME-MoM (de' Michieli Vitturi et al., 2015). The model is an extension of the Eulerian steady-state volcanic plume model presented in Barsotti et al. (2008) (derived from Bursik (2001)), where the method of moments is adopted to describe the polydispersity associated with the multi-phase nature of volcanic plumes. In particular, in the framework of the IAVCEI inter-compariosn study (Costa et al., this issue), the model is used to investigate the parameters exerting a major control on plume height (Mastin et al., 2009; Degruyter and Bonadonna, 2012), by applying it to a weak plume scenario (based on 26 January 2011 Shinmoe-dake eruptive conditions) and a strong plume scenario (based on the climatic phase of the 15 June 1991 Pinatubo eruption; Fig. 1).

In addition, the results allow us to numerically investigate the relation between eruptive mass flux and plume height. Typically this relation is characterised by a power law, with plume height increasing with the fourth root of the eruption rate (Settle, 1978; Sparks et al., 1997; Mastin et al., 2009). However, compilation of observed and estimated plume heights and eruption rate data by Mastin et al. (2009) highlight considerable variability in these observations. Studies by Degruyter and Bonadonna $(2012,2013)$ and Woodhouse et al. (2013) showed that part of this variability can be attributed to the effect of wind, entrainment coefficients, source temperature, specific heat and buoyancy frequency on the eruptive column, hypotheses that are further developed herein.

\section{Methods}

\subsection{Plume Model}

The integral plume model PLUME-MoM (de' Michieli Vitturi et al., 2015) is used here to describe the rise in the atmosphere of a mixture of gas and particles during an explosive eruption. The model is based on an extension of the simple plume model of Morton et al. (1956) to the volcanic context, accounting for the effect of atmospheric wind which results in the bending of the plume trajectory and an increase in the entrainment of ambient air (Hewett et al., 1971; Bursik, 2001; Barsotti et al., 2008). The model solves equations for the conservation of mass, momentum, energy and two additional equations for heat capacity and mixture gas constant, assuming thermal equilibrium between solid and gaseous phases. The model accounts 
for particle fallout and for this reason the grain-size distribution changes continuously during plume rise. Effects of aggregation (Folch et al., 2015), re-entrainment of particles after release (Bursik, 2001; Folch et al., 2015), or effects of humidity in the atmosphere (Degruyter and Bonadonna, 2012; Devenish , 2013; Folch et al., 2015; Mastin, 2014; Woodhouse et al., 2013) are not considered.

In order to properly track the evolution of the particle size distribution, PLUME-MoM adopts the method of moments (Marchisio and Fox, 2013). This technique is based on a population balance equation describing the particle size distribution in terms of a density function as, for example, the number of particles per unit volume, or the mass fraction of particles, as a function of particle diameter. Some integral quantities of interest (i.e. the moments) can be defined from the density function and their transport equations are derived from the population balance equation. The particular definition of the moments enables a direct physical interpretation; in particular, it is possible to define the mean and standard deviation of the particle size distribution in terms of the first three moments. Thus, solving for the first three transport equations of the moments, we are able to track changes in the parameters most commonly used to characterize particle distribution.

For a detailed description and derivation of the equations solved by the model the reader can refer to de' Michieli Vitturi et al. (2015), while a brief overview is provided in the Appendix.

\subsection{Uncertainty Quantification and Sensitivity analysis}

Numerical modeling of volcanic columns is commonly used to determine inputs for ash dispersal models. It is therefore critical to systematically assess uncertainty associated with the model and its sensitivity to the input parameters. Although uncertainty quantification and sensitivity analysis are becoming more common practices in volcanology, there is still significant confusion and interchange of the two terms. For this reason, we report here the two definitions used in this work:

- Uncertainty quantification (UQ) is the forward propagation of uncertainty to predict the overall uncertainty in model outputs;

- Sensitivity analysis (SA) is the study of how the uncertainty in model output can be apportioned to different sources of uncertainty in model inputs. 
This subtle difference is depicted in Fig. 2, representing the results of multiple model runs in terms of a probability distribution of the output values (UQ) and the relative weight of the input parameters in determining the variability of the model output (SA). From the diagram, it is clear that the relative weights obtained with the sensitivity analysis alone do not provide any information on output values or on the amount of variability in the output, and thus ideally uncertainty and sensitivity analysis should be conducted concurrently. A partial reason for the confusion between the two analysis is due to the fact that the techniques adopted to perform UQ and SA are the same in most cases. In volcanology, for example, a Monte Carlo approach with multiple simulations with random sampling of the input variables is frequently used to perform both uncertainty quantification and sensitivity analysis (e.g. Scollo et al., 2008). These methods rely on repeated random sampling of input parameters to obtain numerical results, and to describe through statistical analysis of the results model uncertainty and sensitivity of the output (Fig. 2).

Here we conduct both uncertainty quantification and sensitivity analysis using the PLUME-MoM model. The sources of uncertainty considered in this work are those prescribed for some common inputs and parameters of volcanic column integral models in the framework of the inter-comparison study, presented in Costa et al. (this issue). In particular, among the different sources of epistemic uncertainty (Rougier et al., 2013; Woodhouse et al., 2015), structural (or model-related) uncertainty, related to the inability of the model to describe accurately all the physical processes occurring within the plume, and thus accounting for limitations that cannot be eliminated by calibrating the parameters, is not considered here. An example of structural uncertainty in our integral plume model is neglection of the thermodynamic effects of phase changes of water in the plume.

In this work, the input variables are independent of each other and the Latin hypercube sampling method has been adopted to sample the parameter space (Iman et al., 1980). The range of each uncertain variable is divided into $N_{s}$ segments of equal probability, where $N_{s}$ is the number of samples requested (i.e. the number of simulations to perform); for each of the uncertain variables, a sample is selected randomly from each of these equal probability partitions (with only one sample in each partition; inset Fig. 2). These $N_{s}$ values for each of the individual parameters are then combined in a shuffling operation to create a set of $N_{s}$ parameter vectors with a specified correlation structure. In this way, we do not vary a single input parameter at a time 
but in each couple of simulations taken from the $N_{s}$ samples, all of the input parameters have different values. In comparison to Monte Carlo sampling, Latin hypercube sampling has the advantage that every row and column in the resulting sample set has exactly one sample, and thus a smaller number of samples is required to cover the entire parameter space.

For some of the tests presented here, Latin hypercube sampling has been combined with a global sensitivity analysis, allowing the response of the model to input parameters to be investigated statistically, and enabling key dependencies of the model to be identified. Here, the open source DAKOTA toolkit was applied (Adams et al., 2011), using a variance based method. Variance-based decomposition is a global sensitivity method that summarizes how the variability in model output can be apportioned to the variability in individual input variables (Saltelli et al., 2010; Scollo et al., 2008). This sensitivity analysis uses two primary measures, the main effect sensitivity index $S_{i}$ and the total effect index $T_{i}$, also called the Sobol indices. The main effect sensitivity index corresponds to the fraction of the variability in the output, $Y$, that can be ascribed to input $x_{i}$ alone by comparing the variance of the conditional expectation $\operatorname{Var}_{x_{i}}\left[E\left(Y \mid x_{i}\right)\right]$ against the total variance $\operatorname{Var}(Y)$, enabling identification of the input variables with first order effect on model output. The total effects index corresponds to the fraction of the uncertainty in the output, $Y$, that can be attributed to input $x_{i}$ and its interactions with other variables. In both cases, a larger index implies a greater reliance of the output on the input parameter. These indices are calculated by:

$$
S_{i}=\frac{\operatorname{Var}_{x_{i}}\left[\left(Y \mid x_{i}\right)\right]}{\operatorname{Var}(Y)}
$$

and

$$
T_{i}=\frac{E\left(\operatorname{Var}\left(Y \mid x_{-i}\right)\right)}{\operatorname{Var}(Y)}
$$

where $Y=f(x)$ and $x_{-i}=\left(x_{1}, \ldots, x_{i-1}, x_{i+1}, \ldots, x_{m}\right)$. In comparison, model output uncertainty is simply presented as a distribution of model results for the given input parameters (Fig. 2).

\section{Results}

\subsection{Reference cases}

In the first instance, we present the results obtained for four reference cases, as defined by the IAVCEI plume models inter-comparison study (Costa 
et al., this issue): weak plume with no wind, weak plume into wind, strong plume with no wind and strong plume into wind (input parameters provided in Table 1). We observe that this definition is different from that generally adopted, where a weak plume is a bent-over plume where upward velocity is generally lower than horizontal wind velocity, but have retained the terminology for consistency with that adopted for the inter-comparison study. The weak plume scenario with wind is based on the eruptive and atmospheric conditions of the 26 January 2011 Shinmoe-dake eruption (Hashimoto et al., 2012; Suzuki and Koyaguchi, 2013; Kozono et al., 2013). In the first stage of the eruption, three volcanic plumes formed and were strongly affected and bent by a westerly wind. Weather radar echo recorded plume heights of 6.5 to $8.5 \mathrm{~km}$ above sea level (Shimbori and Fukui, 2012). The atmospheric conditions used for the weak plume cases are taken from the Japan Meteorological Agency's Non-Hydrostatic Model (Hashimoto et al., 2012) for Shinmoe-dake volcano at 00 JST, 27 January 2011 (for more details on the atmospheric conditions and plots of the wind profiles the reader can refer to Fig. 1 in Costa et al. (this issue)).

The strong plume scenario with wind is based on the climactic phase of the Pinatubo eruption, Philippines, on 15 June 1991 (Holasek et al., 1996; Costa et al., 2013). Geostationary Meteorological Satellite (GMS) and NOAA polar-orbiting Advanced Very High Resolution Radiometer (AVHRR) satellite images of the eruption plumes showed maximum eruption column altitudes of up to $40 \mathrm{~km}$ asl. The atmospheric profiles for the strong plume cases were obtained from the European Centre for Medium-Range Weather Forecast (ECMWF) for Pinatubo volcano at 13:40 PLT of 15 June 1991. These data only cover the lower $37.5 \mathrm{~km}$ and for simulations exceeding this height the atmospheric conditions have been extrapolated with constant values. At heights greater than this, we assume that the atmospheric conditions remain constant, and do not vary with height. It is also worth noting that wind conditions for the Shinmoe-dake and the Pinatubo eruptions are very different (see Fig. 1 in Costa et al. (this issue)), with a maximum wind intensity of about $80 \mathrm{~m} / \mathrm{s}$ at $10 \mathrm{~km}$ asl for the weak scenario (average value of $\approx 40 \mathrm{~m} / \mathrm{s}$ ) and a maximum of about $20 \mathrm{~m} / \mathrm{s}$ at $15 \mathrm{~km}$ for the strong scenario (with an average value of $\approx 12 \mathrm{~m} / \mathrm{s}$ ).

For the analysis presented here, weak and strong cases are defined in terms of final plume height ( 6 and $37 \mathrm{~km}$ above the vent in the weak and strong plume case, respectively) or mass flux $(1.50 \mathrm{E}+06$ and $1.50 \mathrm{E}+09 \mathrm{~kg} / \mathrm{s}$ in the weak and strong plume case, respectively). For the reference runs, 


\begin{tabular}{ccccccc} 
Sim & $\begin{array}{c}\text { Wind } \\
\text { effects }\end{array}$ & $\begin{array}{c}\text { Plume } \\
\text { Height }(\mathrm{m})\end{array}$ & $\begin{array}{c}\text { MFR } \\
(\mathrm{kg} / \mathrm{s})\end{array}$ & $\begin{array}{c}\text { Temp } \\
(\mathrm{K})\end{array}$ & $\begin{array}{c}\text { Init Vel } \\
(\mathrm{m} / \mathrm{s})\end{array}$ & $\begin{array}{c}\mathrm{H}_{2} \mathrm{O} \\
\text { wt } \%\end{array}$ \\
\hline WP1 & $\mathrm{N}$ & $* *$ & $1.50 \mathrm{E}+06$ & 1273 & 135 & 3 \\
WP2 & $\mathrm{N}$ & 6000 & $* *$ & 1273 & 135 & 3 \\
WP3 & $\mathrm{Y}$ & $* *$ & $1.50 \mathrm{E}+06$ & 1273 & 135 & 3 \\
WP4 & $\mathrm{Y}$ & 6000 & $* *$ & 1273 & 135 & 3 \\
SP1 & $\mathrm{N}$ & $* *$ & $1.50 \mathrm{E}+09$ & 1053 & 275 & 5 \\
SP2 & $\mathrm{N}$ & 37000 & $* *$ & 1053 & 275 & 5 \\
SP3 & $\mathrm{Y}$ & $* *$ & $1.50 \mathrm{E}+09$ & 1053 & 275 & 5 \\
SP4 & $\mathrm{Y}$ & 37000 & $* *$ & 1053 & 275 & 5
\end{tabular}

Table 1: Input parameters used for the four test cases, where WP refers to weak plume and SP to strong plume. For each reference case either the plume height or mass flow rate (MFR) was used as the input parameter. The desired mass flow rate was obtained varying the radius at the base of the plume.

entrainment coefficients of 0.09 and 0.5 are used for radial $(\alpha)$, and wind $(\beta)$ entrainment, respectively. Such values of the entrainment coefficients were proven to be reasonably consistent with observations of recent welldocumented events (Barsotti and Neri, 2008; Spinetti et al., 2013) and with values determined from large-eddy numerical simulations (Devenish et al., $2010)$. For the weak plumes the initial particle distribution is the sum of two Gaussian distributions (in the $\phi$ scale) having modes set at $\phi=0$ (with $\rho=$ $2200 \mathrm{~kg} / \mathrm{m}^{3}$ ) and $\phi=4$ (with $\rho=2700 \mathrm{~kg} / \mathrm{m}^{3}$ ) with a standard deviation of $\sigma=1.6$. For the strong plumes a finer grain-size distribution is assumed with modes at $\phi=1$ (with $\rho=2500 \mathrm{~kg} / \mathrm{m}^{3}$ ) and $\phi=6\left(\right.$ with $\rho=2700 \mathrm{~kg} / \mathrm{m}^{3}$ ). The other parameters, prescribed by the plume model inter-comparison study (Costa et al., this issue) and common for all the tests, are reported in Table 2. It is worth noting that the heat capacity values were kept constant for all the analyses presented here and thus sensitivity of model results to these parameters is not quantified. Nevertheless, Woodhouse et al. (2015) have shown, through an uncertainty analysis of a model of wind-blown volcanic plumes considering the effect of heat capacity, that such variability of specific heat capacities could be influential on some model results.

Model solutions for the reference cases are presented in Fig. 3. Crosssectional areas from the weak plume examples (Fig. 3A and 3B) show that at the same height, under wind conditions, plume radius (calculated as normal 


\begin{tabular}{lcc} 
Parameter & Value & Units \\
\hline Specific heat of solid pyroclasts & 1100 & $\mathrm{~J} /(\mathrm{kg} \mathrm{K})$ \\
Specific heat of volcanic gas (H20) at constant volume & 1348 & $\mathrm{~J} /(\mathrm{kg} \mathrm{K})$ \\
Specific heat of air at constant volume & 717 & $\mathrm{~J} /(\mathrm{kg} \mathrm{K})$ \\
Specific heat of volcanic gas (H20) at constant pressure & 1810 & $\mathrm{~J} /(\mathrm{kg} \mathrm{K})$ \\
Specific heat of air at constant pressure & 1000 & $\mathrm{~J} /(\mathrm{kg} \mathrm{K})$ \\
Gas constant of volcanic gas (H20) & 462 & $\mathrm{~J} /(\mathrm{kg} \mathrm{K})$ \\
Gas constant of air & 287 & $\mathrm{~J} /(\mathrm{kg} \mathrm{K})$ \\
Gravitational acceleration & 9.80665 & $\mathrm{~m} / \mathrm{s}^{2}$ \\
Vent elevation & 1500 & $\mathrm{~m}$
\end{tabular}

Table 2: Common parameters used for the four test cases. The only volcanic gas considered in the tests is water.

to the plume centerline) is much greater than for no wind conditions, related to entrainment due to wind. Comparison of plume velocity with height (Fig. 3 , right panels) shows noticeable differences in plume profiles for each of the cases investigated. In all four weak plume simulations, the plume velocity decreases with height, while in the strong plume case, there is an initial decrease in velocity, leading to a phase of acceleration, due to the large entrainment and heating of atmospheric air and the associated increase in buoyancy, followed by a further decrease in velocity. Such velocity patterns lead to the classification of these plumes as superbuoyant following Bursik and Woods (1991).

In both the weak and strong plume examples, the modelled maximum plume height (height at which vertical velocity becomes zero) is greater under no wind conditions. This is particularly true for the weak plume case, where the addition of wind results in a bent over plume (Fig. 3B), reducing maximum plume height by a significant amount. While there is a noticeable reduction in plume height for the strong plume in wind, the plume retains its structure, and is not bent over. Similarly, the neutral buoyancy level (NBL, highlighted by the open symbol in the right hand panels of Fig. 3), determined as the height at which the density of the plume mixture equals that of the ambient, varies remarkably for the weak plume examples, with a range of almost $5 \mathrm{~km}$, more than half of the maximum plume height. In the strong plume example however, the NBL for the different simulations are very similar. It is important to remark that for the analysis presented here 
both plume height and neutral buoyancy level are determined as those along the centerline, and maximum height at the upper plume edge is greater than that on the centerline in the presence of wind, as clearly shown in the middle panels of Fig. 3.

The vertical velocity at neutral buoyancy level (NBL) ranges from about $42 \mathrm{~m} / \mathrm{s}$ for the weak plume example under no wind conditions where the initial mass flow rate (MFR) is specified, to about $12 \mathrm{~m} / \mathrm{s}$ for the same initial mass flow rate with wind. In comparison to the weak plume case, the results from the strong plume simulations show that profiles with height are similar under both no wind and wind conditions. The velocity at NBL ranges between about $267 \mathrm{~m} / \mathrm{s}$ for the simulation where the initial mass flow rate is specified and under no wind conditions, to about $243 \mathrm{~m} / \mathrm{s}$ for the same initial mass flow rate under wind conditions.

\section{2. $M F R$ vs height}

The relationship between mass eruption rate and plume height has been extensively studied in the past, both theoretically and experimentally (Morton et al., 1956; Settle, 1978; Sparks et al., 1997; Mastin et al., 2009). Maximum plume height is largely controlled by thermal flux at the vent, the stratification and moisture content of the atmosphere, and the volatile content of the magmatic mixture. Thermal flux, related to the mass eruption rate, is the most important factor and it has been shown that column height increases approximately with the fourth root of eruption rate. This powerlaw relationship agrees well with observations of historic eruptions and results from integral models for strong plumes, but does not provide accurate predictions for weak plumes (Carey and Bursik, 2015).

Here the relationship between initial mass flow rate and final column height was characterized by varying the column height by $\pm 20 \%$ with respect to the reference value for both the weak and strong plumes, and the mass eruption rate, ranging from $1 / 5$ to 5 times the reference values (Fig. 4). For the weak plume case with no wind, a change in column height of $\pm 20 \%$ results in a change in the mass eruption rate from about $-54 \%$ to $+130 \%(-45 \%$ to $+113 \%$ with wind). For the strong plume case, results in no wind and wind conditions are similar, whereby a change in column height of $\pm 20 \%$ results in a change in mass eruption rate from $-65 \%$ to $+117 \%$ for the simulations without wind and from $-64 \%$ to $+119 \%$ for the simulations with wind. For the weak plume case without wind, increasing the initial eruption rate to $5 \times$ that of the reference run resulted in an increase in plume height from the 
reference result of 8.8 to $13.2 \mathrm{~km}$ (3.9 to $6.5 \mathrm{~km}$ with wind), and decreasing the eruption rate by $5 \times$ resulted in a plume height of $6.5 \mathrm{~km}(2.7 \mathrm{~km}$ in the wind example). Please note that here, in comparison to results presented in Fig. 3, height values are calculated above the vent. For the strong plume case without wind, increasing the initial eruption rate by $5 \times$ resulted in an increase in plume height from 38.6 to $48.8 \mathrm{~km}$ (34.6 to $48.3 \mathrm{~km}$ with wind), and decreasing the eruption rate by $5 \times$ resulted in a plume height of 27.4 $\mathrm{km}(24.4 \mathrm{~km}$ in the wind example).

\begin{tabular}{lccc} 
& $\tilde{a}$ (95\% c.b.) & $b(95 \%$ c.b. $)$ & $R^{2}$ \\
\hline Weak, no wind & $388.3(322.9-453-6)$ & $0.222(0.210-0.234)$ & 0.995 \\
Weak, wind & $67.04(48.35-85.73)$ & $0.288(0.270-0.306)$ & 0.995 \\
Strong, no wind (all) & $795.1(306.8-1283)$ & $0.183(0.154-0.212)$ & 0.965 \\
Strong, no wind $<37.5 \mathrm{~km}$ & $463.3(436.2-490.3)$ & $0.209(0.206-0.212)$ & 0.999 \\
Strong, wind (all) & $373.1(308.4-437.9)$ & $0.214(0.206-0.222)$ & 0.998 \\
Strong, wind $<37.5 \mathrm{~km}$ & $356.8(326.6-386.9)$ & $0.216(0.212-0.220)$ & 0.999
\end{tabular}

Table 3: Fitting coefficients with $95 \%$ confidence bounds for mass flow rate $(\mathrm{kg} / \mathrm{s})$ versus plume height $(\mathrm{m})$ above the vent for the weak and strong plume under the no and strong wind conditions shown in Fig. 4. The exponent $b$ is the same as in Eq. (3), i.e. it is independent from the use of mass flow rate versus volumetric flow rate and from the units of plume height, while the coefficient $\tilde{a}$ is the prefactor of the power law and has different values according to the variable used for the flow rate and the units chosen for plume height.

In both cases, an increase in mass flow rate $(\mathrm{kg} / \mathrm{s})$ resulted in an increase in plume height (meters above the vent) which can be described by a powerlaw (Table 3.2), with an exponent close to that obtained by Mastin et al. (2009) whereby a best-fit line was fit to observational data:

$$
H=a V^{b}=2.0 \cdot V^{0.241}
$$

where $V$ is the volumetric flow rate ( $m^{3}$ DRE per second) obtained from the mass flow rate (please note that the use of mass or volumetric flow rate does not change the exponent of the power law) and $H$ is plume height above the vent expressed in kilometers. It is worth noting that the use of mass flow rate instead of volumetric flow rate and meters instead of kilometers for plume height does not affect the exponent of the power law, while the prefactor coefficient differs by two orders of magnitude. 
In the simulations presented in Fig. 4 there is a significant difference in results and power-law trends for the no wind and wind examples in the weak plume example, where increasing the mass flow rate results in a greater increase in plume height under no wind conditions. These differences were not accounted for in the original power-law equation (3), as presented in Mastin et al. (2009), since the dataset included both eruptions without and with wind effects (although the latter are of a limited number). In comparison, results from the strong plume example show much smaller differences between the no wind and wind case. Again, an increase in mass flow rate results in an increase in plume height with similar fitting coefficients between the two sets of simulations. In both of the strong wind examples, two powerlaw fits were applied, one to those results with heights within the ascribed atmospheric conditions, and one to all of the data including those runs with simulated maximum heights greater than those for which atmospheric data was provided. While there is little change between the power-law fits for the wind case, there is a significant difference between the fits for simulations under no wind conditions.

From Fig. 4 it is possible to quantify the change in the eruption rate necessary to keep the same plume height when wind is considered. For the weak plume with a height of $4800 \mathrm{~m}(-20 \%$ with respect to the reference height) a mass flow rate of $Q=2.9 \times 10^{6} \mathrm{~kg} / \mathrm{s}$ is required, with respect to a mass flow rate of $Q_{0}=9.5 \times 10^{5} \mathrm{~kg} / \mathrm{s}$ for the no wind conditions, resulting in a relative change $\Delta Q_{r e l}=\left(Q-Q_{0}\right) / Q_{0} \approx 30$. For a weak plume with an height of $7200 \mathrm{~m}(+20 \%$ with respect to the reference height) a relative change of $\Delta Q_{\text {rel }} \approx 22$ is necessary. These values drastically reduce for the strong plume, for which $\Delta Q_{\text {rel }} \approx 0.7$ for values of the plume height in the range $29.6-44.4 \mathrm{~km}$ ( $\pm 20 \%$ with respect to the reference height). According to the equation derived by Degruyter and Bonadonna (2012) and Bonadonna et al. (2015), for a fixed plume height $h$, the change in mass flow rate $\Delta Q$ (see Fig. 4) required to reach the height when wind is present is given by:

$$
\frac{\Delta Q}{Q_{0}}=\frac{1-\Pi}{\Pi}
$$

where $Q_{0}$ is the mass flow rate for the no-wind condition and $\Pi$ is a dimensionless number quantifying which of the two fundamental terms controlling plume dynamics is dominant (radial expansion vs wind entrainment):

$$
\Pi=6 \frac{2^{5 / 2}}{z_{1}^{4}} \frac{\bar{N} h}{\bar{v}}\left(\frac{\alpha}{\beta}\right)^{2} .
$$


In equation (5), $z_{1}$ is the maximum non-dimensional height of Morton et al. (1956) and its value of 2.8 was determined by numerical integration, $\bar{N}$ is the average buoyancy frequency $(1 / \mathrm{s}), \bar{v}$ is the average wind velocity $(\mathrm{m} / \mathrm{s})$ and $\alpha$ and $\beta$ are the radial and wind entrainment coefficients, respectively. Large values of $\Pi$ imply that the radial entrainment term is more important and the plume would mostly develop in a vertical manner with only a small effect of the wind on plume rise. If we apply equation (5) to the plume height and mass flow rates described above, we obtain values in the same range as those illustrated in Fig. 5, with a relative change $\Delta Q_{r e l}$ ranging from 20 to 30 times for the weak plume when height is varied from $7200 \mathrm{~m}$ to $4800 \mathrm{~m}$, and from 0.7 to 1.5 times for the strong plume when height varies from 44.4 $\mathrm{km}$ to $29.6 \mathrm{~km}$.

\subsection{Uncertainty Quantification and Sensitivity Analysis}

The simulations presented in the previous section highlight the effect of wind on the relation between mass flow rate and plume height. Here we present a thorough analysis of the model to investigate model response to a number of input parameters. The response of the model to uncertainty in entrainment (both radial and wind) coefficients, initial velocity, temperature, water fraction and wind intensity are of particular interest. It is important to note that some of these parameters directly control the mass flow rate, and thus the plume height. For application of uncertainty quantification and sensitivity analysis, a range of values was provided for each input, following a uniform distribution (i.e. no one value is more likely than another).

Entrainment of air into the eruption plume plays a major role in controlling the rise of the eruptive column and in the past several values have been proposed for the entrainment coefficients (Costa et al., this issue). In the original paper of Morton et al. (1956), for example, a value of 0.093, based on best fit, was proposed for radial entrainment while in Suzuki and Koyaguchi (2010) a range of 0.05-0.15 was suggested, with values increasing with height for well mixed plumes. For wind entrainment coefficient, Suzuki and Koyaguchi (2015) obtained values as low as 0.1 from numerical simulations, Devenish et al. (2010) uses 0.5, while the original paper of Bursik (2001) and a number of other works thereafter use a value of 1 . Here, as a first analysis, the effect of entrainment on modelled results was investigated by performing 400 simulations for each of the case examples, varying both $\alpha$ (denoting radial entrainment) in the interval [0.05;0.15], and $\beta$ (describing entrainment associated with wind) in the interval [0.1;1.0]. It is important 


\begin{tabular}{lcccc} 
Sim & $\begin{array}{c}\text { 5\%ile } \\
(\mathrm{m})\end{array}$ & $\begin{array}{c}50 \% \text { ile } \\
(\mathrm{m})\end{array}$ & $\begin{array}{c}\text { 95\%ile } \\
(\mathrm{m})\end{array}$ & $\begin{array}{c}\text { Mean } \\
(\mathrm{m})\end{array}$ \\
\hline Weak plume, wind & 3189.7 & 4049.3 & 6752.9 & 4450.7 \\
Weak plume, no wind & 7399.1 & 8478.9 & 11176.4 & 8776.4 \\
Strong plume, wind & 29015.6 & 33794.6 & 41574.4 & 34359 \\
Strong plume, no wind & 31419.6 & 36788.0 & 47816.3 & 38013
\end{tabular}

Table 4: Uncertainty quantification results presenting percentiles and mean values of the distributions of plume heights for the reference cases, when $\alpha$ (denoting radial entrainment) varies in the interval $[0.05 ; 0.15]$, and $\beta$ (describing entrainment associated with wind) varies in the interval $[0.1 ; 1.0]$.

to note again that wind conditions for the weak and the strong plume are different, with an average wind of about $40 \mathrm{~m} / \mathrm{s}$ for the weak scenario and about $12 \mathrm{~m} / \mathrm{s}$ for the strong scenario. Varying wind speed directly affects the amount of atmospheric air entrainment associated with wind.

The values of column height versus the two entrainment coefficients are plotted in Fig. 5 for the four reference cases with fixed mass flux $(1.50 \mathrm{E}+06$ and $1.50 \mathrm{E}+09 \mathrm{~kg} / \mathrm{s}$ in the weak and strong plume case respectively). For the weak plume with no wind example (Fig. 5A), the $5^{\text {th }}$ percentile height is 7.4 $\mathrm{km}$, median is $8.5 \mathrm{~km}$ and $95^{\text {th }}$ percentile is $11.1 \mathrm{~km}$, compared to $3.2 \mathrm{~km}$, $4.0 \mathrm{~km}$ and $6.7 \mathrm{~km}$ respectively for the weak plume with wind (Fig. 5B). For the strong plume with no wind example (Fig. 5C), the $5^{\text {th }}$ percentile height is $29 \mathrm{~km}$, median is $33.8 \mathrm{~km}$ and $95^{\text {th }}$ percentile is $41.5 \mathrm{~km}$, and $31.4 \mathrm{~km}$, $36.7 \mathrm{~km}$ and $47.8 \mathrm{~km}$ respectively for the strong plume with wind (Fig. 5D). Additional percentiles and mean heights are reported in Table 3.3.

The results can be generalised by an increase in entrainment resulting in a decrease in maximum plume height. For both the strong and weak wind examples under no wind conditions, $\alpha$ controls plume height when no other parameters are varied, with higher values relating to lower maximum plume heights and height going as the square root of $\alpha$, according to the scaling of Morton et al. (1956). When the effects of entrainment due to wind dominate, a square root relationship between plume height and $\beta$ can be expected (Hewett et al., 1971). This is also shown in Fig. 5B for the weak plume in wind example, highlighting a distinct correlation between $\beta$ and plume height. In the strong plume under wind conditions, the relation between $\alpha$ and $\beta$ is more complex than in the weak plume case, even for the 
smaller wind intensity. In this example, the larger the value of $\beta$, the smaller the effect of changes in $\alpha$ on plume height. This result is also demonstrated by analysis of model uncertainty. While distributions for weak plume no wind, weak plume in wind, and strong plume no wind simulations are similar, described by a maximum at lower plume heights with a tail to greater heights, the strong plume in wind results have a noticeably different distribution. This is because this is the only example for which both variables (the two entrainment coefficients) have a comparable and first-order effect.

The effect of particle sedimentation on resultant plume height was investigated by conducting a number of simulations both with and without particle loss (Table 4). The results are striking in that sedimentation of particles appears to have very little impact on both the maximum height attained (less than $0.5 \%$ difference), and the grain-size distribution of particles within the plume at the maximum height. Changes in the parameters characterizing the particle size distribution are larger for the weak plume and for the coarser mode, with the greatest change obtained for the weak plume with wind where the mean grain size decreases from $0 \phi$ at the vent to $0.57 \phi$ at the top of the plume (corresponding to $1 \mathrm{~mm}$ and $0.67 \mathrm{~mm}$ respectively). For the strong plumes, inclusion of sedimentation results in a change of the grain-size mode of the order of $0.1 \phi$ for the coarse mode, and $0.01 \phi$ for the fine mode between the vent and the top of the plume. These results appear consistent with those of Woodhouse et al. (2013) and de' Michieli Vitturi et al. (2015), where a limited sensitivity of plume height to the initial grain-size distribution is observed. In fact, despite the different patterns in particle loss with height obtained when changing initial grain-size distributions, the range of variations of the column height is quite small. As shown in de' Michieli Vitturi et al. (2015), this is due to the large amount of air entrained in the first kilometers of the convective thrust region, making the contribution of the solid fraction to the overall dynamics of the plume small, when compared to that of the gas.

Finally, for each reference case, we fixed the vent diameter and the response of the model to typical uncertainties on several input parameters (defined in the IAVCEI inter-comparison study, see Costa et al. (this issue)) was explored, varying them simultaneously with Latin hypercube sampling: exit velocity $( \pm 20 \%)$, exit temperatures $\left( \pm 100{ }^{\circ} \mathrm{C}\right)$, water fraction $( \pm 2 \mathrm{wt} \%)$ and wind intensity $( \pm 20 \%)$ with respect to the reference values (Table 1$)$. We observe that changes in the first three of these parameters directly affect the source mass flow rate and consequently plume height, although to different 


\begin{tabular}{lcccccc} 
Simulation & $\begin{array}{c}\text { Plume Height } \\
(\mathrm{m})\end{array}$ & $\begin{array}{c}\mathrm{NBL} \\
(\mathrm{m})\end{array}$ & $\begin{array}{c}\mu_{1} \\
(\phi)\end{array}$ & $\begin{array}{c}\sigma_{1} \\
(\phi)\end{array}$ & $\begin{array}{c}\mu_{2} \\
(\phi)\end{array}$ & $\begin{array}{c}\sigma_{2} \\
(\phi)\end{array}$ \\
\hline Weak, no wind PL & 8836 & 6760 & 0.57 & 1.62 & 4.16 & 1.51 \\
Weak, no wind NPL & 8819 & 6750 & 0 & 1.6 & 4 & 1.6 \\
Weak, wind PL & 3930 & 3139 & 0.33 & 1.61 & 4.1 & 1.55 \\
Weak, wind NPL & 3917 & 3130 & 0 & 1.6 & 4 & 1.6 \\
Strong, no wind PL & 38615 & 24545 & 1.09 & 1.59 & 6.01 & 1.59 \\
Strong, no wind NPL & 38553 & 24530 & 1 & 1.6 & 6 & 1.6 \\
Strong, wind PL & 34631 & 22597 & 1.07 & 1.59 & 6.01 & 1.59 \\
Strong, wind NPL & 34613 & 22592 & 1 & 1.6 & 6 & 1.6
\end{tabular}

Table 5: Plume heights, and grainsize distribution parameters of the mixture at the plume top for simulations with and without sedimentation. The subscripts 1 and 2 refer to the coarse and fine classes of particles, respectively. NBL stands for neutral buoyancy level. $\mathrm{PL}=$ particle loss, $\mathrm{NPL}=$ no particle loss.

degrees. Application of a global sensitivity analysis with 1500 simulations enables investigation of model output, in this case maximum plume height, in relation to the provided range of input parameters.

Results are again described by a density distribution of maximum plume heights, with a $5^{\text {th }}$ percentile of $7.9 \mathrm{~km}$, median of $8.8 \mathrm{~km}$ and $95^{\text {th }}$ of percentile of $10.9 \mathrm{~km}$ for the weak plume with no wind, and $3.4 \mathrm{~km}, 4.0 \mathrm{~km}$ and $5.3 \mathrm{~km}$ respectively for the weak plume in wind (see Fig. 6). The results for the weak plume, in both the no wind and wind case, show that there is a remarkable correlation between initial water fraction, and the final plume height, with lower initial water fractions resulting in greater column heights. In comparison, there is no distinct correlation between initial temperature and wind and plume height, however, initial velocity does have a weak control. It is also worth noting that for all weak plume simulations the column is fully convective with no indication of column collapse.

These results may be described in terms of the model sensitivity to a particular input. Sensitivity indices for the weak plume simulations (Fig. 7) support the results in Fig. 6, where it is shown that the initial water fraction has the greatest control on the plume height attained. These results are reflected in the large main Sobol indices, showing initial water fraction has a first order control on plume height. In both the no wind and wind simulations, the initial velocity has some control, while when wind is taken 


\begin{tabular}{lcccc} 
Sim & $\begin{array}{c}5 \% \text { ile } \\
(\mathrm{m})\end{array}$ & $\begin{array}{c}50 \% \text { ile } \\
(\mathrm{m})\end{array}$ & $\begin{array}{c}\text { 95\%ile } \\
(\mathrm{m})\end{array}$ & $\begin{array}{c}\text { Mean } \\
(\mathrm{m})\end{array}$ \\
\hline Weak plume, no wind & 7908.8 & 8835.1 & 10941.1 & 9063.1 \\
Weak plume, wind & 3386.6 & 3956.7 & 5266.1 & 4098.9 \\
Strong plume, no wind & 4755.1 & 37942.9 & 43978.2 & 36362 \\
Strong plume, no wind (buoyant) & 35354.8 & 38288.9 & 44162.7 & 38826 \\
Strong plume, wind & 31125.4 & 34438.4 & 39101.3 & 34359 \\
Strong plume, wind (buoyant) & 31304.5 & 34476.5 & 39120.5 & 34829
\end{tabular}

Table 6: Uncertainty quantification results showing percentiles and mean values of the distributions of plume heights for the reference cases, when several input parameters are varied with respect to the reference values: exit velocity $( \pm 20 \%)$, exit temperatures $( \pm 100$ $\left.{ }^{\circ} \mathrm{C}\right)$, water fraction $( \pm 2 \mathrm{wt} \%)$ and wind intensity $( \pm 20 \%)$. For the strong plumes, in addition to the values computed from all the simulations, the values obtained excluding the runs producing collapsing columns are also reported.

into account, variation in wind speed is a key factor. The total sensitivity indices also highlight the importance of the initial water fraction, being more important in the no wind case.

Uncertainty results for the strong plume case (Fig. 8) look considerably different to those from the weak plume case (Fig. 6). In this case, column collapse is predicted for $7.1 \%$ of the examples with no wind, and $1.33 \%$ of the examples with wind. The additional entrainment due to wind enables many of the runs that collapse under no wind conditions to entrain enough air to become buoyant. The column heights attained for the buoyant (i.e. not including collapsed examples) strong plumes are $35.3 \mathrm{~km}, 38.3 \mathrm{~km}$ and 44.2 $\mathrm{km}$, for the $5^{\text {th }}, 50^{\text {th }}$ and $95^{\text {th }}$ percentiles respectively for the strong plume with no wind, and $31.3,34.5$ and $39.1 \mathrm{~km}$ for the strong plume under wind. Again, the results show a strong correlation between initial water content and final plume height, and a weaker correlation between final plume height and initial velocity and temperature, with no correlation between wind speed and final plume height in this case. In the case of the strong plume examples, there is also a correlation between the initial temperature and the final plume height, a correlation which is not as evident in the weak plume example (Fig. $6)$.

For the strong plume case, the Sobol indices for column height are not presented. This is due to the fact that in this case, in contrast to the weak plume case, simulation results, as shown in Fig. 8, reflect two different trends 
(Engwell et al., 2014): changes in column regime (buoyant or collapsing) and changes in plume height (mostly for buoyant plumes). This makes it difficult to associate Sobol indices with a control over the regime or the height. From Fig. 8, for example, it appears that velocity has a first order control on column regime, but water fraction has a dominant control on plume height; these two correlations cannot be expressed by a single global number such as the Sobol index. Again, this result highlights a potential limitation of using global sensitivity analysis alone and the utility of a combined UQ and SA approach.

In the previous analysis, vent diameter was fixed allowing the mass flow rate to change with the input parameters. When the vent diameter is changed in order to keep a constant mass flow rate $(1.5 \mathrm{E}+05$ and $1.50 \mathrm{E}+09 \mathrm{~kg} / \mathrm{s}$ in the weak and strong plume respectively), the uncertainty in modelled plume height is drastically reduced. The response of the model to the same uncertainties in the input parameters investigated in the previous analysis (Fig. 6 and Fig. 8), but keeping the mass flow rate constant, is presented in Fig. 9. Again, results are obtained changing all parameters simultaneously with Latin hypercube sampling. For the weak plume in no wind (Fig. 9A), when the parameters are changed in the investigated intervals and mass flow rate is kept constant changing vent diameter, we observe variations in column height in the range $\pm 2 \%$. The plots clearly show the dominant control of exit temperature on column height, with a minor effect of exit velocity and negligible effects of the other parameters. For the weak plume with wind (Fig. $9 \mathrm{~B})$, a larger variation in column height is obtained $( \pm 8 \%)$, and variation in wind speed is a key factor. It is worth noting that, even if the mass flow rate is kept constant, for both strong plumes without and with wind (Fig. 9C and Fig. 9D respectively), low values of the exit velocity (and to a lesser degree, exit temperature and water fraction) promote column collapse. In both cases, there is a velocity threshold above which the plume is always buoyant. For the strong case without wind (Fig. 9C), considering the buoyant plumes only, we observe variations in column height in the range $\pm 9 \%$, while for the buoyant strong plumes a smaller range is obtained $( \pm 6 \%)$ when wind is considered (Fig. 9C). In both the cases, temperature has the greatest control on the column height attained. 


\section{Discussion and concluding remarks}

The sensitivity results presented here show that, for the considered vent diameters and input uncertainty ranges, the dominant eruption source parameters controlling the plume height are the same for the weak and strong plume case, with both being strongly affected by the initial water fraction, while initial velocity and temperature have a lesser effect. As previously stated, when vent diameter is held constant, changes in exit velocity, exit temperature and water fraction directly affect the source mass flow rate and consequently plume height, although to different degrees. As an example, increasing the temperature of the weak plume reference case by $100{ }^{\circ} \mathrm{C}$, while keeping the other vent parameters constant (including vent diameter), results in a decrease of mass flow rate from $1.50 \mathrm{E}+06$ to $1.39 \mathrm{E}+06 \mathrm{~kg} / \mathrm{s}(-7.3 \%)$, while an increase in water fraction from $3 \mathrm{wt} \%$ to $5 \mathrm{wt} \%$, results in a decrease of mass flow rate from the reference value to $9.01 \mathrm{E}+05 \mathrm{~kg} / \mathrm{s}(-39.93 \%)$. As a result of the lower mass flow rate, such an increase in initial water fraction only, results in a decrease in the final column height of the weak reference case with wind of $11.37 \%$. Note that, when water fraction is increased, less entrained air is required for the mixture to reach the same density as the ambient and intrude horizontally into the atmosphere at neutral buoyancy. When the power law given by Eq. (3) is applied to the weak case without wind as shown in Fig. 6A, an increase in the water fraction from $1 \mathrm{wt} \%$ to 5 wt $\%$ gives roughly a factor of 6 decrease in initial density and mass flow rate and a decrease in plume height by a factor of $6^{0.241} \approx 1.54$. However, sensitivity analysis results show that the same range of variation in plume height is attained when uncertainty of the entrainment parameters is considered while using the reference eruptive source parameters (see Fig. 5). Increasing $\alpha$ and $\beta$ results in greater amounts of ambient air being entrained at a given height which acts to cool the plume leading to an increase in plume density (and therefore a decrease in plume buoyancy) and consequently a decrease in maximum plume height. A range of entrainment coefficients have been used in the literature when using plume models to reproduce observations, however entrainment coefficients, and particularly that associated with wind, are still poorly constrained. In the simulations conducted, entrainment is assumed to be constant with height, following the studies of Morton et al. (1956) and the early volcanic plume works of Sparks (1986) and Woods (1988). More recently, however, variable entrainment has been presented whereby the entrainment coefficient is dependent on the Richardson number of the plume 
(Carazzo et al., 2008), resulting in less entrainment in the gas thrust region of the plume where the density of the plume is greater than the ambient, and an increase in entrainment as the density of the plume decreases to less than that of the ambient. In general, relative to the values of 0.09 and 0.5 used in this paper, the use of this variable entrainment assumption results in a decrease in modelled plume height (Engwell et al., 2014). It is worth noting that, when the vent diameter is changed in order to keep constant mass flow rate, the uncertainty in modelled plume height is drastically reduced, and exit temperature is the dominant parameter in controlling column height, except for the weak plume in wind where the wind intensity has a larger control. It is also worth mentioning that the main controls on plume height, as found with the sensitivity analysis, do not account for the effect of conduit vent geometry (e.g. Koyaguchi et al. (2010)) and for the mutual relationships between conduit flow and plume dynamics which introduce further dependences between the flow variables at the vent (see Colucci et al. (2014) for a comprehensive sensitivity analysis of such a coupled system).

The examples presented in Fig. 3 show that the neutral buoyancy levels are strongly correlated with maximum plume height, with a greater difference between maximum plume height and neutral buoyancy height as maximum plume height increases. Here neutral buoyancy level and maximum plume height are defined as the heights at which the plume density equals that of the ambient and the vertical velocity decreases to zero, respectively. Therefore the plume continues to rise above the neutral buoyancy level due to inertia, and continues to entrain ambient air. The result of this additional air entrainment is a further reduction in the mixture density, meaning that the height at which the plume intrudes laterally may be greater than that of the neutral buoyancy level as defined above. However, it is worth mentioning that 1D integral models such as PLUME-MoM are not able to describe the complex fountaining behaviour of the umbrella cloud, thus providing an oversimplification of the dynamics of this region of the plume (see Costa et al. (this issue) and Suzuki et al. (this issue) for further details on this aspect).

The relationship between eruptive mass flux and the maximum plume height is controlled by the thermal flux, with theoretical studies showing that plume height should increase with the fourth root of eruption rate (Morton et al., 1956). The plume height estimates determined here (Table 2) differ somewhat from this relation, and are in general lower than that proposed by Morton et al. (1956), with the exception of the weak plume in no wind example. Theoretically, the exponent of the power-law relationship should 
increase from 0.25 in the absence of wind to 0.33 for wind dominated plumes (Morton et al., 1956; Hewett et al., 1971; Degruyter and Bonadonna, 2012) and therefore the observed discrepancy can be explained by other effects such as variation of wind speed and temperature with height. Mastin et al. (2009) show that while the empirical trends described in the literature (e.g. Sparks et al. (1997), chapter 5) approximately hold true for observed eruptions, there is some scatter in the data. This scatter was attributed to error in plume height measurements, wind effects, inaccurate volume estimates, or as a result of more complex eruption processes, for example partial collapse of the column and consequent pyroclastic density current formation, or water vapour entrainment. The relation between other parameters, for example wind and the power-law relation are also poorly defined. The results presented here (Table 3) show a relationship between the power-law relation and the effect of wind. For the weak plume example particularly, the power-law coefficient increases notably when wind is taken into account. While this increase is less significant for the strong plume example, results indicate a correlation between power-law coefficient, eruptive mass flux and wind.

It is worth noting that in all of the simulations, the atmospheric profile defined only the lower $37.5 \mathrm{~km}$ of atmosphere. In the cases where the plume reached greater altitudes, the atmospheric conditions (pressure, temperature, humidity and wind velocity) were assumed to be constant with height. Only the strong plume examples attained heights greater than $37.5 \mathrm{~km}$. This assumption did not effect the strong plume in wind results, as shown by the similar power-law fits in Fig. 5 but resulted in very different trends for the simulations with no wind.

In a number of the strong plume examples within the range of input parameters considered here, column collapse occurs and a buoyant plume is not produced, producing results with a maximum column height much lower than for the simulated plumes that become buoyant. Both sets of simulations (strong wind and no wind) are run using the same initial plume parameter ranges, however there are a greater number of collapsed plumes under no wind conditions. Higher rates of entrainment due to wind enables the plume density to reduce enough such that it can become buoyant, resulting in fewer collapsed examples. Degruyter and Bonadonna $(2013,2012)$ also highlight this relation, and suggest that strong winds during the Eyjafjallajokull 2010 and Ruapehu 1996 eruptions resulted in buoyant plume rise where perhaps collapse would have occurred in a still environment. The 
results presented here indicate smaller values of velocity and water fraction favouring collapsing plumes, while temperature and wind change have little effect. Comparison of profiles between a collapsed and buoyant example (see supplementary material) show significant differences in velocity with height. While in both cases, the initial density is greater than that of the ambient, in the collapsing examples, the density does not reach that of the ambient before the vertical velocity decays to zero. It is important to note that the analysis of the strong plume examples highlights a potential limitation of using global sensitivity analysis alone (and thus the utility of a combined UQ and SA approach), because of the inability of Sobol indices to properly describe both changes in column regime and changes in plume height.

While the results presented here are not directly compared to detailed observations of real events, they do provide a number of interesting questions which should be considered when using numerical models to reproduce observations. Perhaps the most obvious result is the comparison of maximum plume height, specifically for bent-over plumes. Typically in numerical modelling studies, maximum height is measured along the centerline of the plume, as in this study. In comparison, measurements of maximum plume height in the field are determined from direct observation, from radar or from satellite imagery (Arason et al., 2011), and typically refer to the uppermost edge of the plume. The results presented herein show that the difference in modelled maximum plume height and the height of the uppermost plume edge can be a number of kilometers, a significant difference when considering plume heights on the order of $10 \mathrm{~km}$, typical of weak plumes. Such a discrepancy could result in greatly inaccurate estimations of eruptive parameters, specifically mass eruption rate if not taken into account.

Finally, it is worth mentioning that the results are only applicable for dry plumes where the energy causing the explosivity is mainly due to the magma volatile content. A specific investigation would be necessary to address phreato-magmatic eruptions where the interaction of magma with different sources of water (liquid and/or solid) controls explosivity (Koyaguchi and Woods, 1996). In such a case the use of a plume model like PLUMEMoM would likely overestimate the mass flux necessary to match the observed plume height, and a dedicated model taking these additional processes into account is required. 


\section{Acknowledgements}

This work has been partially supported by the project MEDiterranean SUpersite Volcanoes (MED-SUV) FP7 ENV.2012.6.4-2 Grant agreement no. 308665 (European Community). S. Engwell was funded by the People Programme (Marie Curie Actions) of the European Union's Seventh Framework Programme (FP7/2007-2013) under the project NEMOH, REA grant agreement no. 289976. The authors warmly thank the Editors of the JVGR Special Issue on eruption plume models, Antonio Costa (INGV, Italy) and Yujiro J. Suzuki (Univ. of Tokyo, Japan). The original version of the manuscript was greatly improved, thanks to the careful work and constructive suggestions of Wim Degruyter, Jeremy Phillips and a third anonymous reviewer.

\section{Appendix A. Model Description}

In this Appendix the equations of the integral model PLUME-MoM are briefly presented. For more details the reader is referred to de' Michieli Vitturi et al. (2015). In contrast with other plume models, where solid particles are partitioned in a finite number of classes with different size, PLUME-MoM assumes a continuous size distribution function $\gamma(\phi)$, representing the mass fraction of particles (mass per unit mass of the gas-particles mixture) with diameter between $\phi$ and $\phi+d \phi$. In this formulation the non-dimensional diameter $\phi$ is expressed in the Krumbein scale:

$$
\phi=-\log _{2}\left(\frac{1000 D}{D_{0}}\right)
$$

where $D$ is the diameter expressed in meters and $D_{0}$ is a reference diameter, equal to $1 \mathrm{~mm}$ (to make the equation dimensionally consistent).

When more than one family of particles are present, for example lithics and pumices, we use the subscript $j$ to distinguish among them. Consequently, $\gamma_{j}(\phi)$ will be the mass concentration of particles of the $j$-th family.

Given a particle size distribution $\gamma_{j}(\phi)$, its "shape" can be quantified through the moments $\Pi_{j}^{(i)}$, defined by

$$
\Pi_{j}^{(i)}=\int_{-\infty}^{+\infty} \phi^{i} \gamma_{j}(\phi) d \phi
$$

The particular definition of $\gamma_{j}(\phi)$ allows a physical interpretation of the moments: for example, the moment $\Pi_{j}^{(0)}$ is the mass fraction of the $j$-th 


\begin{tabular}{|c|c|c|}
\hline Symbol & Definition & Units \\
\hline$C_{m i x}$ & Specific heat capacity of the mixture & $\mathrm{J} \mathrm{kg}^{-1} \mathrm{~K}^{-1}$ \\
\hline$C_{a t m}$ & Specific heat capacity of air & $\mathrm{J} \mathrm{kg}^{-1} \mathrm{~K}^{-1}$ \\
\hline$C_{s, j}$ & Specific heat capacity of $j$-th family particles & $\mathrm{J} \mathrm{kg}^{-1} \mathrm{~K}^{-1}$ \\
\hline $\bar{C}_{s, j}$ & Average specific heat capacity of $j$-th family particles & $\mathrm{J} \mathrm{kg}^{-1} \mathrm{~K}^{-1}$ \\
\hline$D$ & Plume diameter & $\mathrm{m}$ \\
\hline$D_{0}$ & Reference diameter $(1 E-3)$ & $\mathrm{m}$ \\
\hline$p$ & Probability of particles loss & - \\
\hline$r$ & Plume radius & $\mathrm{m}$ \\
\hline$R_{q}$ & Specific gas constant of gas in the mixture & $\mathrm{J} \mathrm{kg}^{-1} \mathrm{~K}^{-1}$ \\
\hline$R_{\text {air }}$ & Specific gas constant of ambient air & $\mathrm{J} \mathrm{kg}^{-1} \mathrm{~K}^{-1}$ \\
\hline$R_{w v}$ & Specific gas constant of water vapour & $\mathrm{J} \mathrm{kg}^{-1} \mathrm{~K}^{-1}$ \\
\hline$s$ & Distance along the plume axis & $\mathrm{m}$ \\
\hline$T$ & Mixture temperature & $\mathrm{K}$ \\
\hline$T_{a t m}$ & Ambient air temperature & $\mathrm{K}$ \\
\hline$u$ & Horizontal component of the plume velocity & $\mathrm{m} \mathrm{s}^{-1}$ \\
\hline$U_{\epsilon}$ & Air entrainment velocity & $\mathrm{m} \mathrm{s}^{-1}$ \\
\hline$U_{a t m}$ & Horizontal wind velocity & $\mathrm{m} \mathrm{s}^{-1}$ \\
\hline$U_{s c}$ & Mixture velocity along the plume axis & $\mathrm{m} \mathrm{s}^{-1}$ \\
\hline$w$ & Vertical component of the plume velocity & $\mathrm{m} \mathrm{s}^{-1}$ \\
\hline$w_{s, j}$ & Settling velocity of $j$-th family particles & $\mathrm{m} \mathrm{s}^{-1}$ \\
\hline$w_{s, j}^{(i)}$ & $i$-th moment of the $j$-th settling velocity & $\mathrm{m} \mathrm{s}^{-1}$ \\
\hline$x^{3,}$ & Horizontal coordinate & $\mathrm{m}$ \\
\hline$x_{s}$ & Mass fraction of particles & $\mathrm{kg} \mathrm{m} \mathrm{m}^{-3}$ \\
\hline$x_{s, j}$ & Mass fraction of the $j$-th family particles & - \\
\hline$y$ & Horizontal coordinate & $\mathrm{m}$ \\
\hline$z$ & Vertical coordinate & $\mathrm{m}$ \\
\hline$\alpha$ & Stream-wise (shear) entrainment coefficient & - \\
\hline$\beta$ & Cross-flow air entrainment coefficient & - \\
\hline$\gamma_{j}$ & Mass concentration of particles of the $j$-th family & $\mathrm{kg} \mathrm{m}^{-3}$ \\
\hline$\omega$ & Angle between the axial direction and the horizon & radians \\
\hline$\phi$ & Diameter in Krumbein scale & - \\
\hline$\Pi_{j}^{(i)}$ & $i$-th moment of the $j$-th mass concentration & $\mathrm{kg} \mathrm{m}^{-3}$ \\
\hline$\rho_{\text {atm }}^{J}$ & Ambient air density & $\mathrm{kg} \mathrm{m} \mathrm{m}^{-3}$ \\
\hline$\rho_{a t m}^{B}$ & Bulk density of the entrained ambient air & $\mathrm{kg} \mathrm{m}^{-3}$ \\
\hline$\rho_{\operatorname{mix}}$ & Mixture density & $\mathrm{kg} \mathrm{m}^{-3}$ \\
\hline$\rho_{w v}^{B}$ & Bulk density of the water vapour & $\mathrm{kg} \mathrm{m} \mathrm{m}^{-3}$ \\
\hline$\theta$ & $\begin{array}{l}\text { Angle in the horizontal plane between the axial } \\
\text { direction and the } x \text {-axis }\end{array}$ & radians \\
\hline
\end{tabular}

Table A.7: List of symbols used in model equations. 
solid phase with respect to the gas-particles mixture, denoted with $x_{s, j}$. It is possible to define a mean particle size in terms of the moments of the mass fraction distribution as $\Pi_{j}^{(i+1)} / \Pi_{j}^{(i)}$; this ratio, for $i=0$, gives the mass averaged diameter, usually denoted with $\mu_{j}$. In addition, the standard deviation $\sigma_{j}$ can be expressed in the terms of the moments.

In the plume model, several quantities characteristic of the particles, such as settling velocity, density and specific heat capacity, are also defined as functions of the particle diameter, and thus we can define their moments in the same manner as for the distribution $\gamma_{j}(\phi)$. In general, for a quantity $\psi_{j}$ function of the diameter $\phi$, we define its moments as

$$
\psi_{j}^{(i)}=\frac{1}{\Pi_{j}^{(i)}} \int_{-\infty}^{+\infty} \psi_{j}(\phi) \phi^{i} \gamma_{j}(\phi) d \phi .
$$

In this case, the moments $\psi_{j}^{(i)}$ can be seen as averaged values of the variable $\phi$, where the index $i$ identifies the weight used for the average. For example, for $i=0, \psi_{j}^{(i)}$ is the mass averaged value.

The equation set for the plume rise model is solved in a $3-\mathrm{D}$ coordinate system $(s, \omega, \theta)$ by considering the bulk properties of the eruptive mixture (Bursik, 2001; Barsotti et al., 2008). The plume is assumed to have a circular section along the curvilinear coordinate $s$, an inclination on the ground defined by an angle $\omega$ between the axial direction and the horizon, and an angle $\theta$ in the horizontal plane $(x, y)$ with respect to the $x$-axis. This last feature is needed to describe the evolution of weak explosive eruptions which are strongly affected by crosswind.

The conservation of flux of particles with size $\phi$ of the $j$-th family is given by:

$$
\frac{d}{d s}\left(\rho_{m i x} \gamma_{j}(\phi) \pi r^{2} U_{s c}\right)=-2 \pi r p w_{s, j}(\phi) \rho_{m i x} \gamma_{j}(\phi)
$$

where $\rho_{\text {mix }}$ is the gas-particles mixture density, $r$ is characteristic plume radius, $U_{s c}$ represents the velocity of the plume cross section along its centerline, $w_{s, j}(\phi)$ is the particle settling velocity (here calculated as in Textor et al. (2006)) and $p$ is a probability that an individual particle will fall out of the plume, defined as a function of radial entrainment coefficient $\alpha$

$$
p=\frac{\left(1+\frac{6}{5} \alpha\right)^{2}-1}{\left(1+\frac{6}{5} \alpha\right)^{2}+1} .
$$


Now, multiplying both the sides of equation (A.4) for $\phi^{i}$ and then integrating over the size spectrum, we obtain the following conservation equations for the moments $\Pi_{j}^{(i)}$ :

$$
\frac{d}{d s}\left(\Pi_{j}^{(i)} \rho_{m i x} U_{s c} r^{2}\right)=-2 r p w_{s, j}^{(i)} \rho_{m i x} \Pi_{j}^{(i)} .
$$

For $i=0$, the equations of conservation of the moments give:

$$
\frac{d}{d s}\left(x_{s, j} \rho_{m i x} U_{s c} r^{2}\right)=-2 r p \rho_{m i x} w_{s, j}^{(0)} x_{s, j} .
$$

expressing the loss of mass flux of the particles of the $j$-th family.

Entrainment, due to both turbulence in the rising buoyant jet and to the crosswind field, is parameterized through the use of two entrainment coefficients, $\alpha$ and $\beta$. Following Hewett et al. (1971), we define the entrainment velocity $U_{\epsilon}$ as a function of windspeed, $U_{a t m}$, as well as axial plume speed, $U_{s c}$ :

$$
U_{\epsilon}=\alpha\left|U_{s c}-U_{a t m} \cos \omega\right|+\beta\left|U_{a t m} \sin \omega\right|,
$$

where $\alpha\left|U_{s c}-U_{a t m} \cos \omega\right|$ is entrainment by radial inflow minus the amount swept tangentially along the plume margin by the wind, and $\beta\left|U_{a t m} \sin \omega\right|$ is entrainment from wind. With this notation, the total mass conservation equation solved by the model becomes

$$
\frac{d}{d s}\left(\rho_{m i x} U_{s c} r^{2}\right)=2 r \rho_{a t m} U_{\epsilon}-2 r p \rho_{m i x} \sum_{j} w_{s, j}^{(0)} \Pi_{j}^{(0)} .
$$

stating that the variation of mass flux (left-hand side term) is due to air entrainment (first right-hand side term) and loss of solid particles (second right-hand side term).

From the variation of mass flux, we can also derive the term accounting for particle loss in the horizontal and vertical momentum equations:

$$
\begin{aligned}
& \frac{d}{d s}\left(\rho_{\text {mix }} U_{s c} r^{2}\left(u-U_{a t m}\right)\right)= \\
& -r^{2} \rho_{\text {mix }} w \frac{d U_{a t m}}{d z}-2 u p r \rho_{\text {mix }} \sum_{j} w_{s, j}^{(0)} \Pi_{j}^{(0)},
\end{aligned}
$$


742

$$
\begin{aligned}
& \left.\frac{d}{d s}\left(\rho_{\text {mix }} U_{s c} r^{2} w\right)\right)= \\
& g r^{2}\left(\rho_{\text {atm }}-\rho_{\text {mix }}\right)-2 w \operatorname{pr} \rho_{\text {mix }} \sum_{j} w_{s, j}^{(0)} \Pi_{j}^{(0)} .
\end{aligned}
$$

where the two components of plume velocity along the horizontal and vertical axes are $u$ and $w$, respectively, and are linked by the relation $U_{s c}=\sqrt{u^{2}+w^{2}}$. In the right-hand side of Eq. (A.10) the terms related to the exchange of momentum due to the wind and to momentum loss from the fall of solid particles appear. Similar contributions are evident in the right-hand side term of Eq. (A.11) where the vertical momentum is changed by the gravitational acceleration term and the loss of particles.

Following the notation adopted above and denoting with $T$ the mixture temperature, the equation for conservation of thermal energy solved by the model writes as

$$
\begin{aligned}
& \frac{d}{d s}\left(\rho_{\text {mix }} U_{s c} r^{2} C_{m i x} T\right)=2 r \rho_{a t m} U_{\epsilon} C_{a t m} T_{a t m} \\
& -r^{2} w \rho_{a t m} g-2 T p r \rho_{m i x} \sum_{j}\left[C_{s, j} w_{s, j}\right]^{(0)} \Pi_{j}^{(0)} .
\end{aligned}
$$

The first term on the right-hand side describes the cooling of the plume due to ambient air entrainment, the second term takes into account atmospheric thermal stratification, and the third term allows for heat loss due to loss of solid particles. Again, this last term is obtained writing the heat loss for the particles of size $D$, and then integrating over the size spectrum. A thermal equilibrium between solid and gaseous phases is assumed. In Eq. (A.12) $C_{a t m}$ and $C_{m i x}$ are the heat capacity of the entrained atmospheric air and of the mixture, respectively, the latter being defined as:

$$
C_{m i x}=\left(1-\sum_{j} x_{s, j}\right) C_{p, g}+\sum_{j} x_{s, j} \bar{C}_{s, j}
$$

and satisfying the following transport equation:

$$
\begin{aligned}
& \frac{\partial C_{\text {mix }}}{\partial s}=\frac{1}{\rho_{\text {mix }} U_{s c} r^{2}}\left[C_{a t m} 2 r \rho_{a t m} U_{\epsilon}-C_{\text {mix }}\left(2 r \rho_{a t m} U_{\epsilon}\right.\right. \\
& \left.\left.-2 r p \rho_{\text {mix }} \sum_{j} w_{s, j}^{(0)} \Pi_{j}^{(0)}\right)-2 p r \rho_{\text {mix }} \sum_{j}\left[C_{s, j} w_{s, j}\right]^{(0)} \Pi_{j}^{(0)}\right] .
\end{aligned}
$$


Similarly, a gas constant $R_{g}$ is defined as a weighted average of the gas constant for the entrained atmospheric air $R_{a t m}$ and the gas constant of the volcanic water vapour $R_{w v}$

$$
R_{g}=\frac{\rho_{a t m}^{B} R_{a t m}+\rho_{w v}^{B} R_{w v}}{\rho_{a t m}^{B}+\rho_{w v}^{B}}
$$

and a conservation equation can be derived, knowing that the variation of gaseous mass fraction with height is solely due to entrained air:

$$
\frac{\partial R_{g}}{\partial s}=\frac{R_{a t m}-R_{g}}{\rho_{\text {mix }}\left(1-x_{s}\right) U_{s c} r^{2}} \cdot 2 r \rho_{a t m} U_{\epsilon},
$$

where $x_{s}$ is the total mass fraction of particles.

Finally, the equations expressing the coordinate transformation between $(x, y, z)$ and $(s, \omega, \theta)$ are given by:

$$
\frac{\partial z}{\partial s}=\sin \omega, \quad \frac{\partial x}{\partial s}=\cos \omega \cos \theta, \quad \frac{\partial y}{\partial s}=\cos \omega \sin \theta .
$$

The plume rise equations are solved with a predictor-corrector Heun's scheme that guarantees a second-order accuracy, keeping the execution time on the order of seconds. A quadrature method of moments (Marchisio and Fox, 2013) has been used to evaluate the integrals defining the moments appearing in the transport equations, as detailed in de' Michieli Vitturi et al. (2015). 


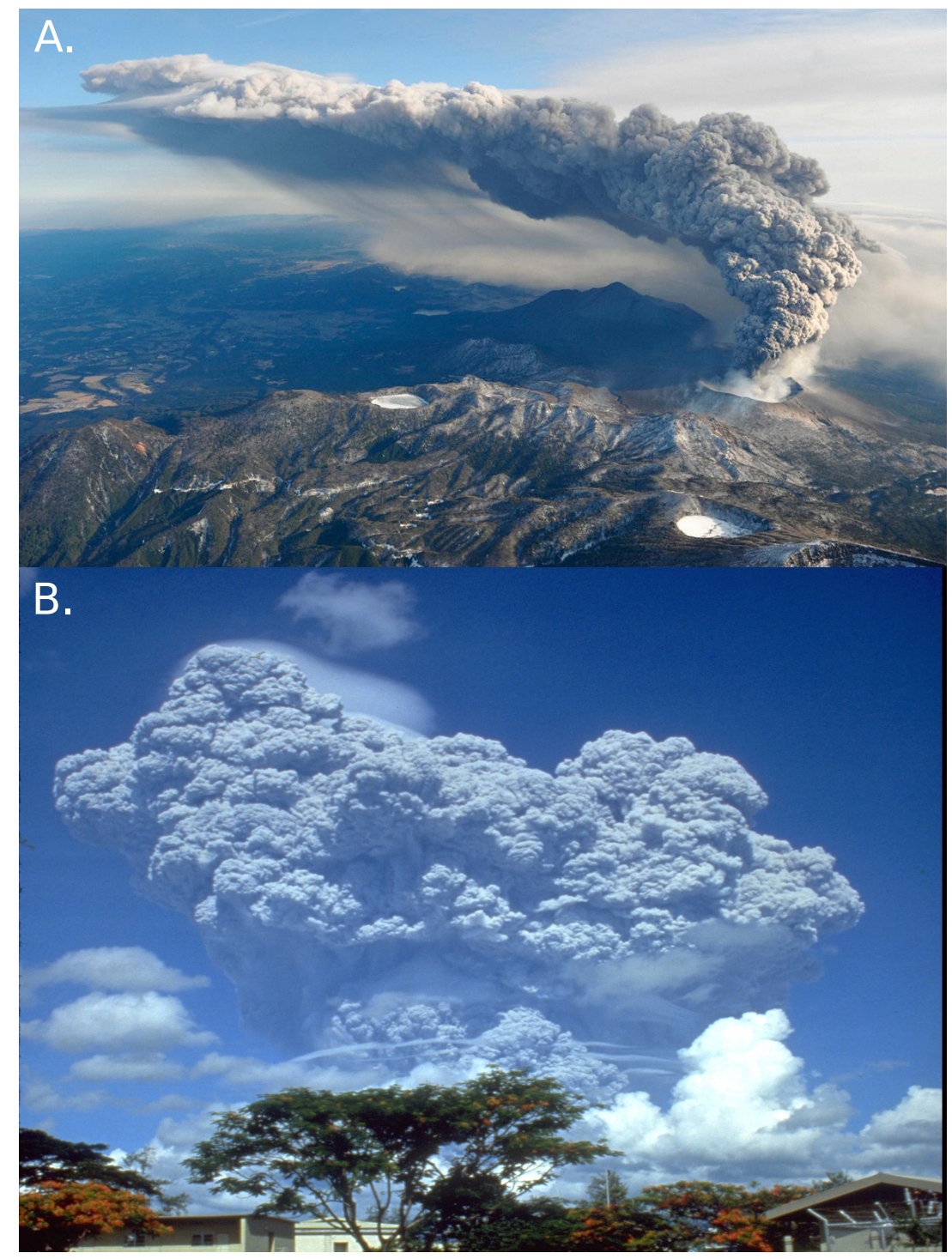

Figure 1: A. Aerial view showing Shinmoe-dake volcano peak erupting between Miyazaki and Kagoshima prefectures on January 27, 2011 (REUTERS/Kyodo) B. The June 12, 1991 eruption column from Mount Pinatubo taken from the east side of Clark Air Base. (U.S. Geological Survey Photograph taken by Richard P. Hoblitt). 

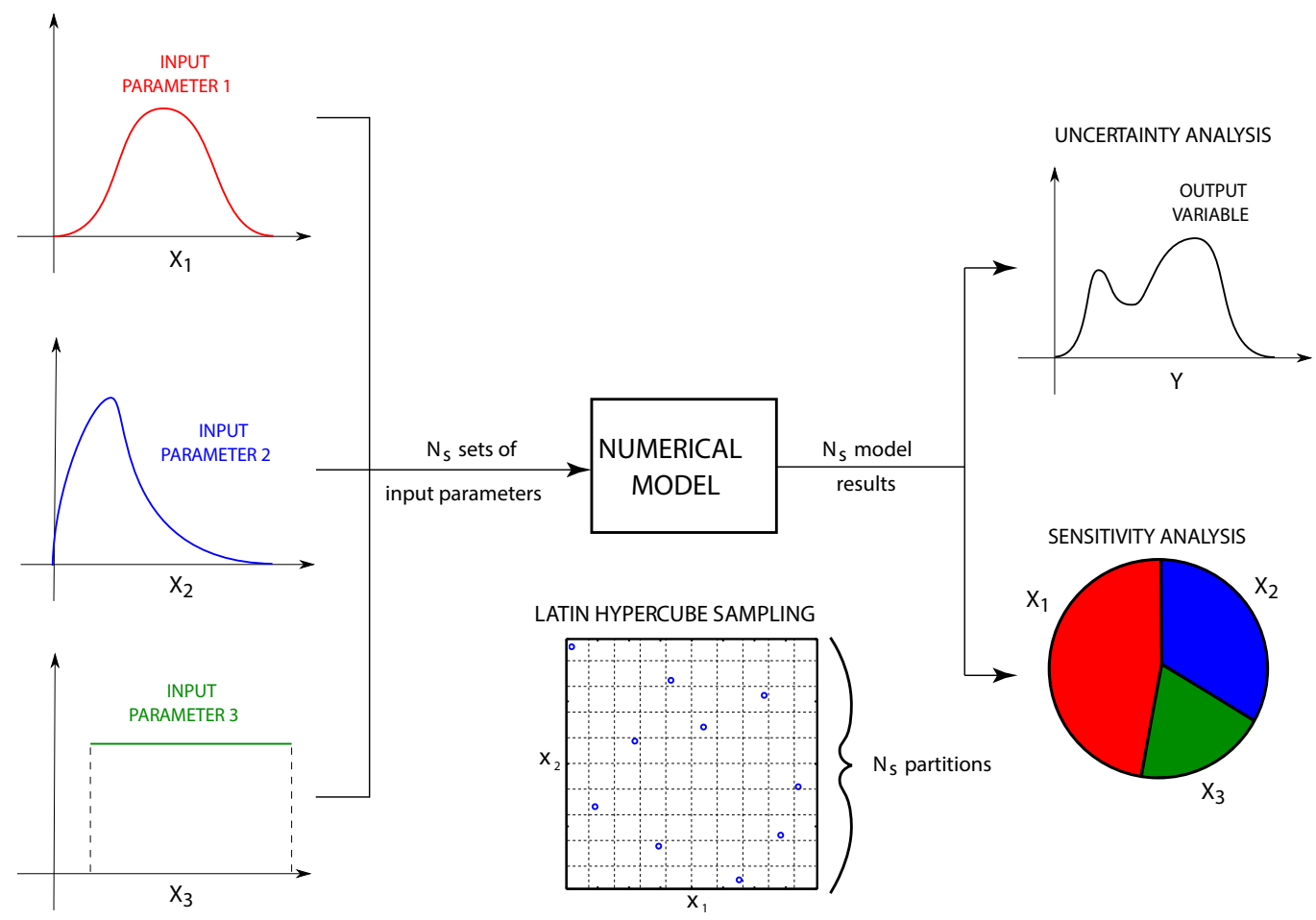

Figure 2: Schematic to illustrate how model uncertainty and sensitivity analysis are defined starting from uncertain input parameters. Please note that $N_{s}$ refers to the number of simulations performed (i.e. the different sets of input parameters) and not the number of input parameters. An example of Latin hypercube sampling is also shown for two input parameters and $N_{s}=10$ sampling points (and thus $N_{s}$ partitions on each axis). Each interval on the two axes contains only one point. 

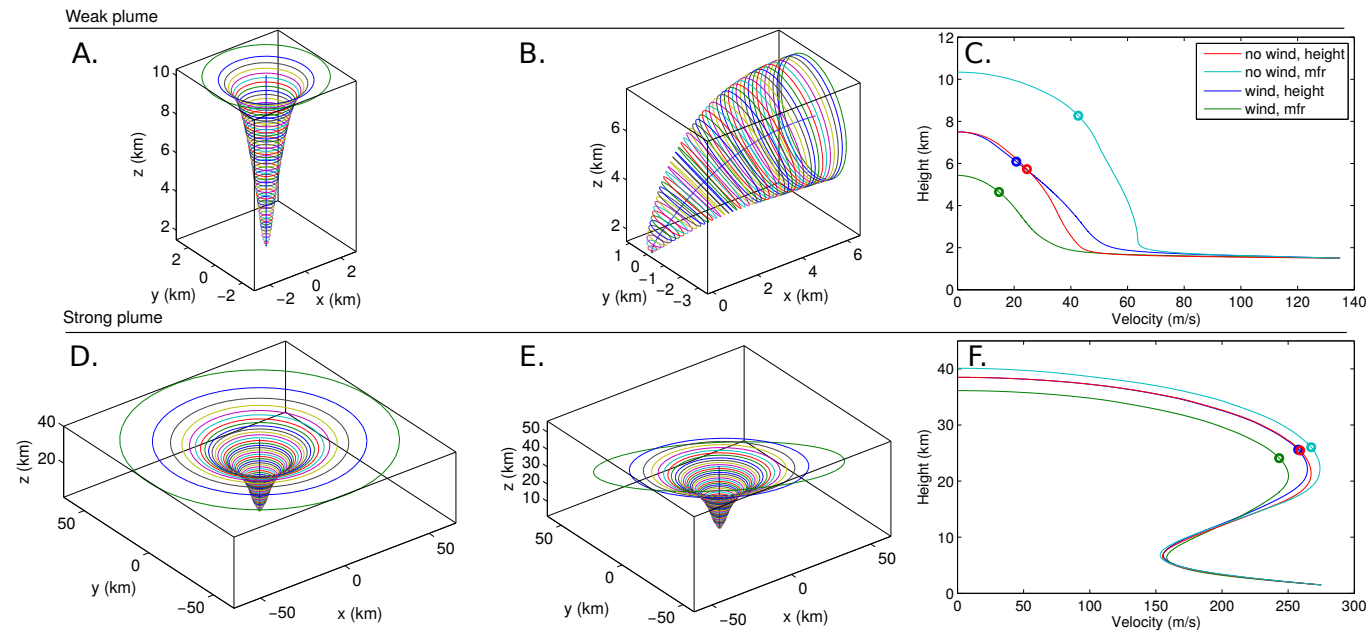

Figure 3: Images of each of the four cases studied with fixed eruption rate and profiles of plume velocity. In the top panels the results for the weak plume are presented: A. plot with no wind (WP1), B. plot into wind (WP3), C. velocity profiles for the no wind and wind conditions, with fixed plume height or fixed mass flow rate. In the bottom panels the results for the strong plume are presented: D. plot with no wind (SP1), E. plot into wind (SP3), E. velocity profiles for the no wind and wind conditions, with fixed plume height or fixed mass flow rate. In all the panels, height refers to height above sea level, vent is at $1.5 \mathrm{~km}$. In the left and middle panels, the blue line denote the centreline of the plume while the circles represent the cross-sectional area. In the right panels, the markers denote the level of neutral buoyancy, determined as the height at which the density of the plume mixture equals that of the ambient. 

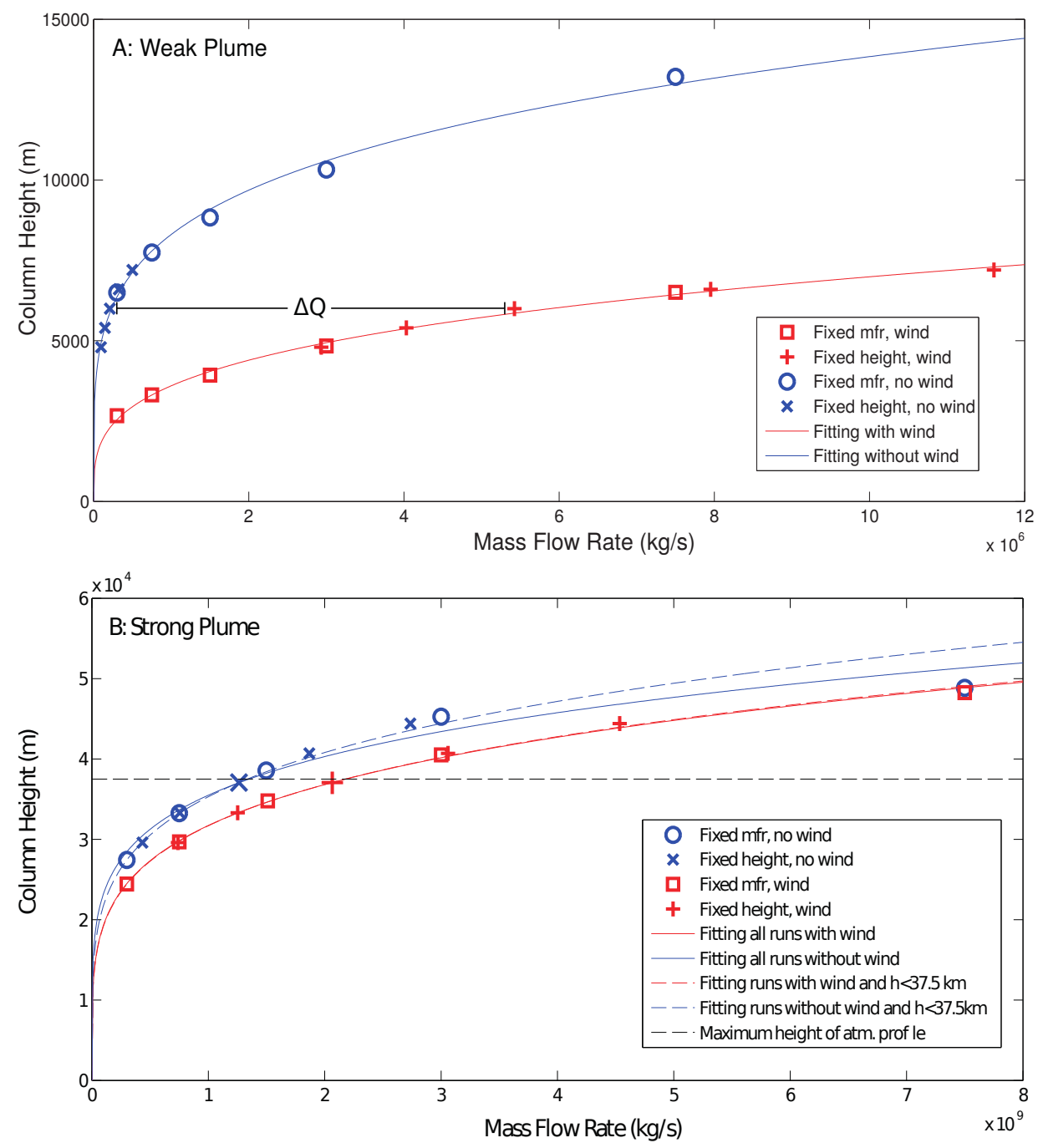

Figure 4: Relationship between initial mass flow rate and final column height characterized by varying the mass eruption rate, ranging from $1 / 5$ to 5 times the reference values, and eruption column height, varying by $\pm 20 \%$ of the reference values of the simulations in Fig. 3 for both the weak plume (A) and strong plume (B) examples. Please note that here, in comparison to Fig. 3, the height above the vent is reported. For the fixed height examples, mass flow rate changes are obtained keeping the initial velocity constant and varying the initial radius. For the reference column height of the weak example $(6000$ $\mathrm{m})$, the change in eruption rate required to retain the same plume height when wind is considered is denoted by $\Delta Q$. In the strong plume example, atmospheric information was only available for the lower $37.5 \mathrm{~km}$, above this height, atmospheric conditions assumed constant. Fit parameters are given in Table 2. 

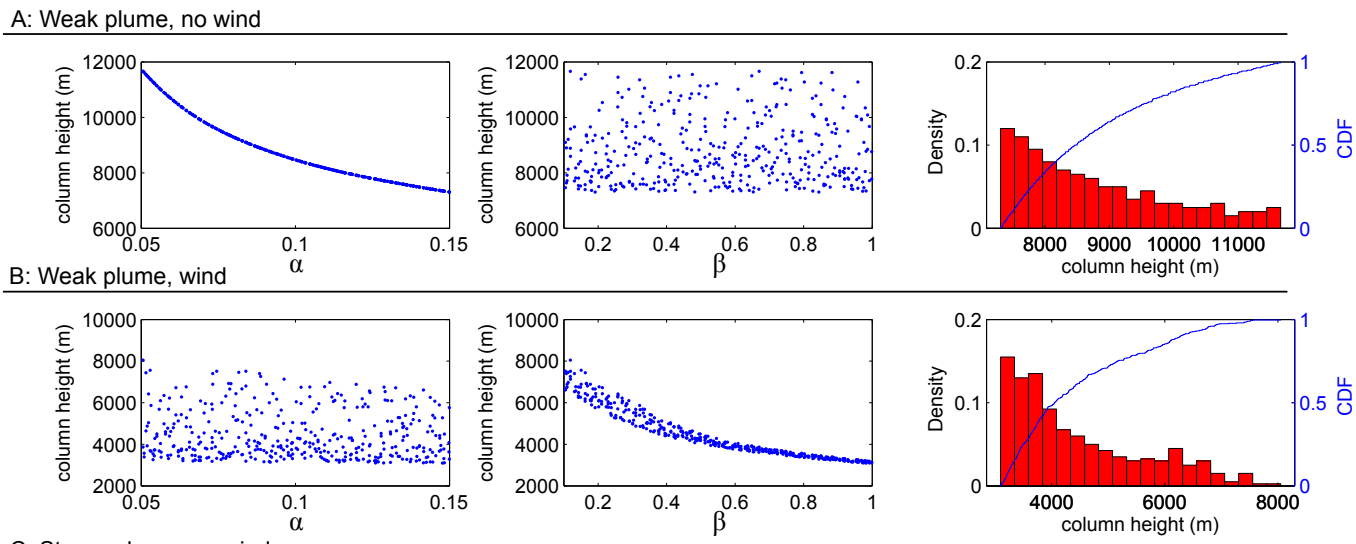

C: Strong plume, no wind
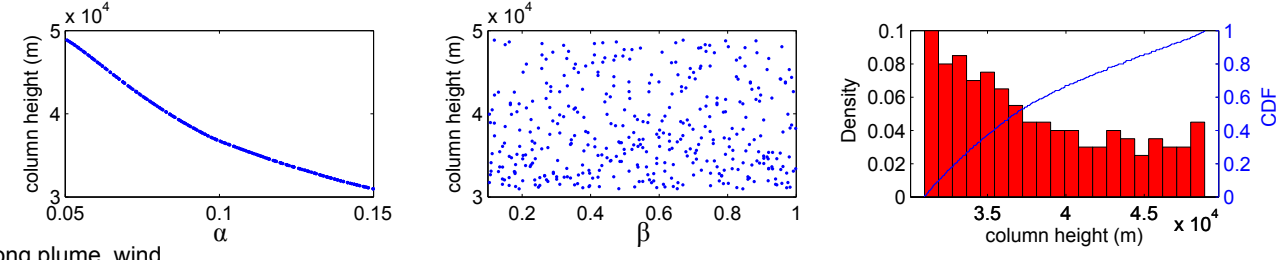

D: Strong plume, wind
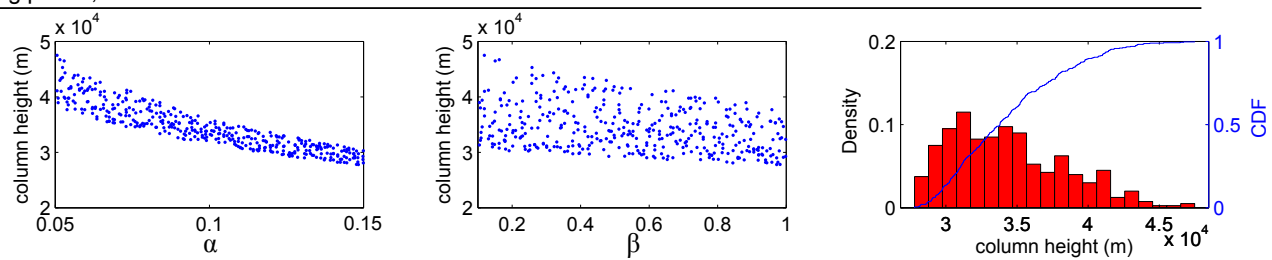

Figure 5: Effect of entrainment parameters, $\alpha$ (left hand column) and $\beta$ (middle column), on maximum plume height (above the vent) for the four reference simulations presented in Fig. 3. The right hand column shows a histogram and cumulative density function of the resultant heights while varying both $\alpha$ and $\beta$. 

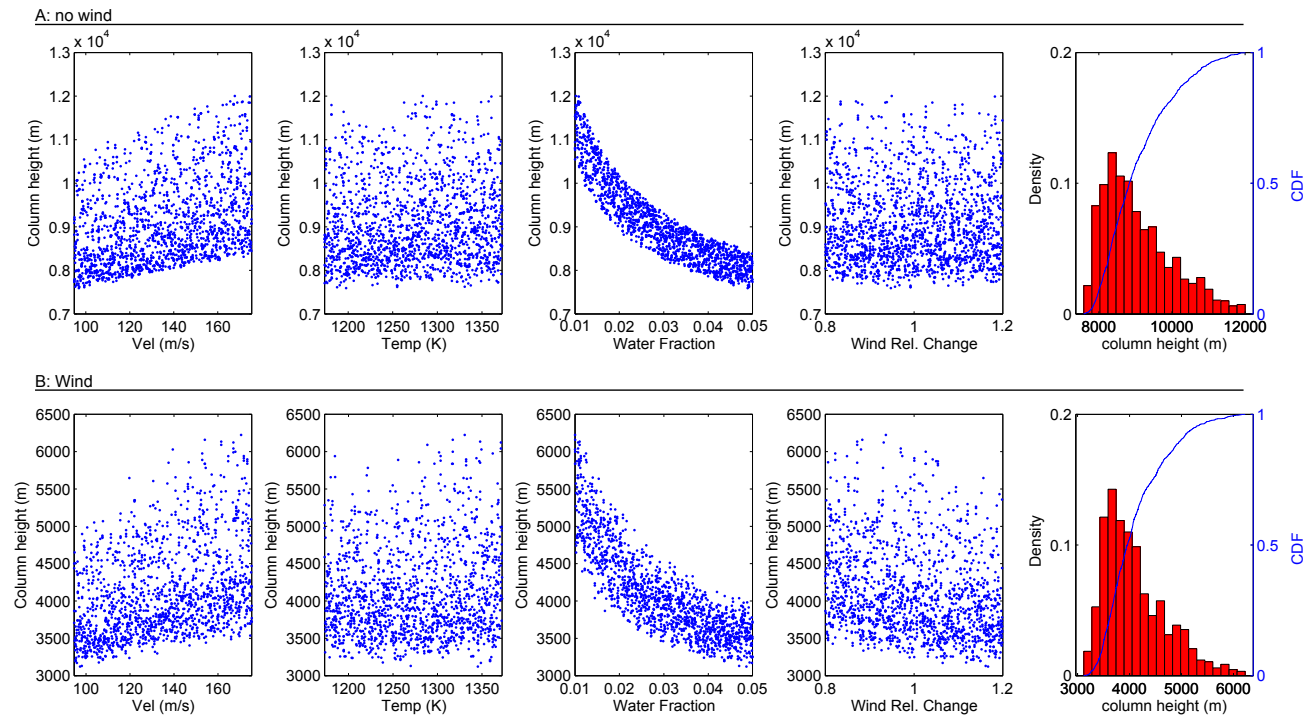

Figure 6: Variation in maximum plume height (above the vent) for each input parameter for the weak plume example. The right hand column shows a histogram and cumulative density function of the resultant modelled heights. The model did not predict plume collapse for any combination of source conditions. 


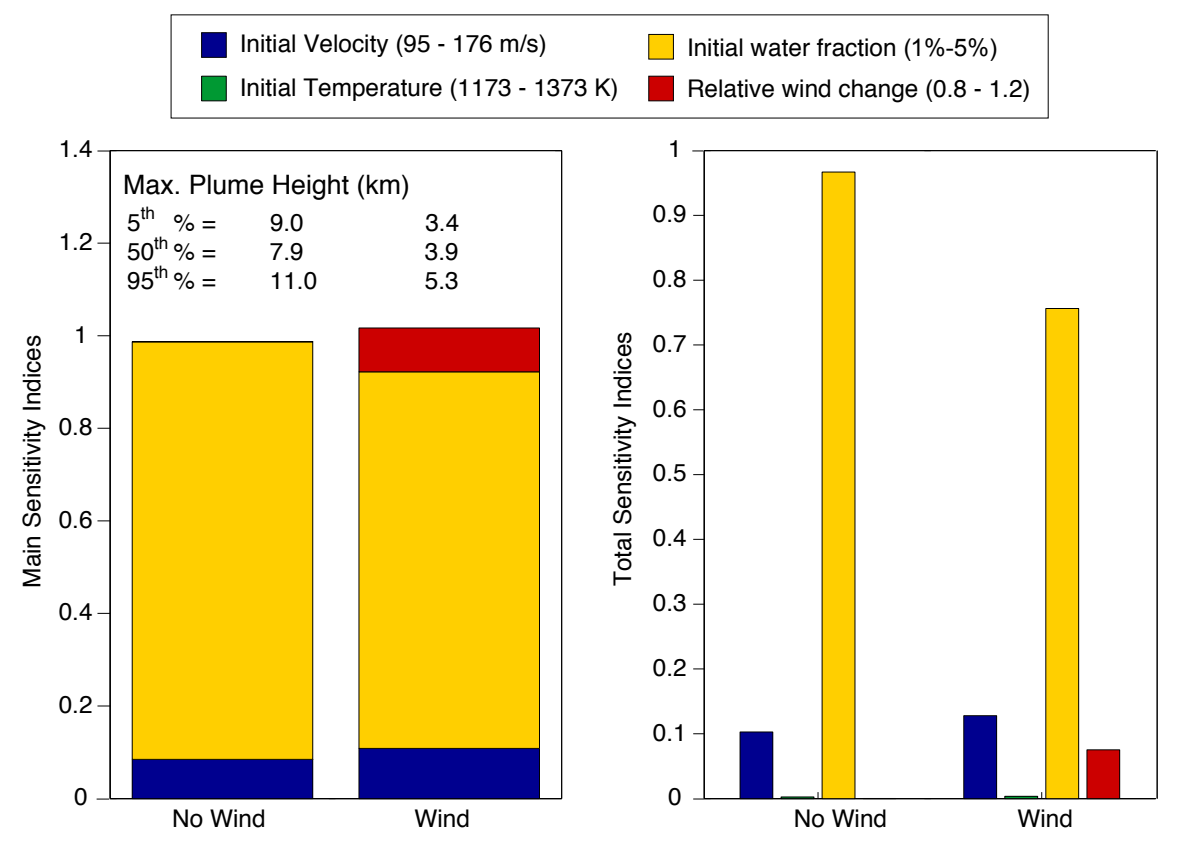

Figure 7: Main and total Sobol indices for the weak plume example in no wind and wind conditions. Main sensitivity indices describe the first order effects between model inputs and outputs, while the total sensitivity indices also include interactions between input parameters within the model. 

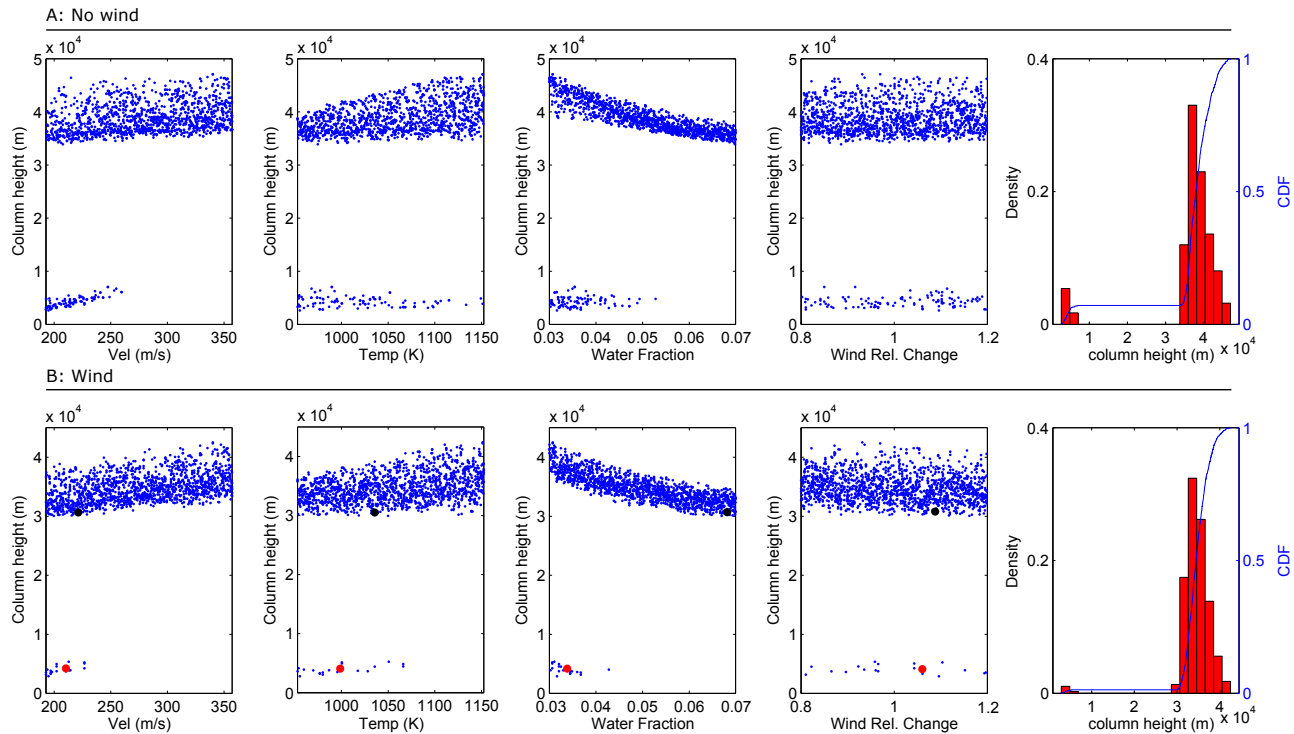

Figure 8: Variation in maximum plume height (above the vent) with input parameters for the strong plume example, with each marker representing a single simulation. Velocity, radius and density profiles for the black symbol, representing a superbuoyant plume, and red symbol, describing a collapsing plume are provided in the supplementary material. The right hand column shows a histogram and cumulative density function of the resultant modelled plume heights. In this case, the histogram is bimodal, reflecting both the buoyant and collapsing regimes. 

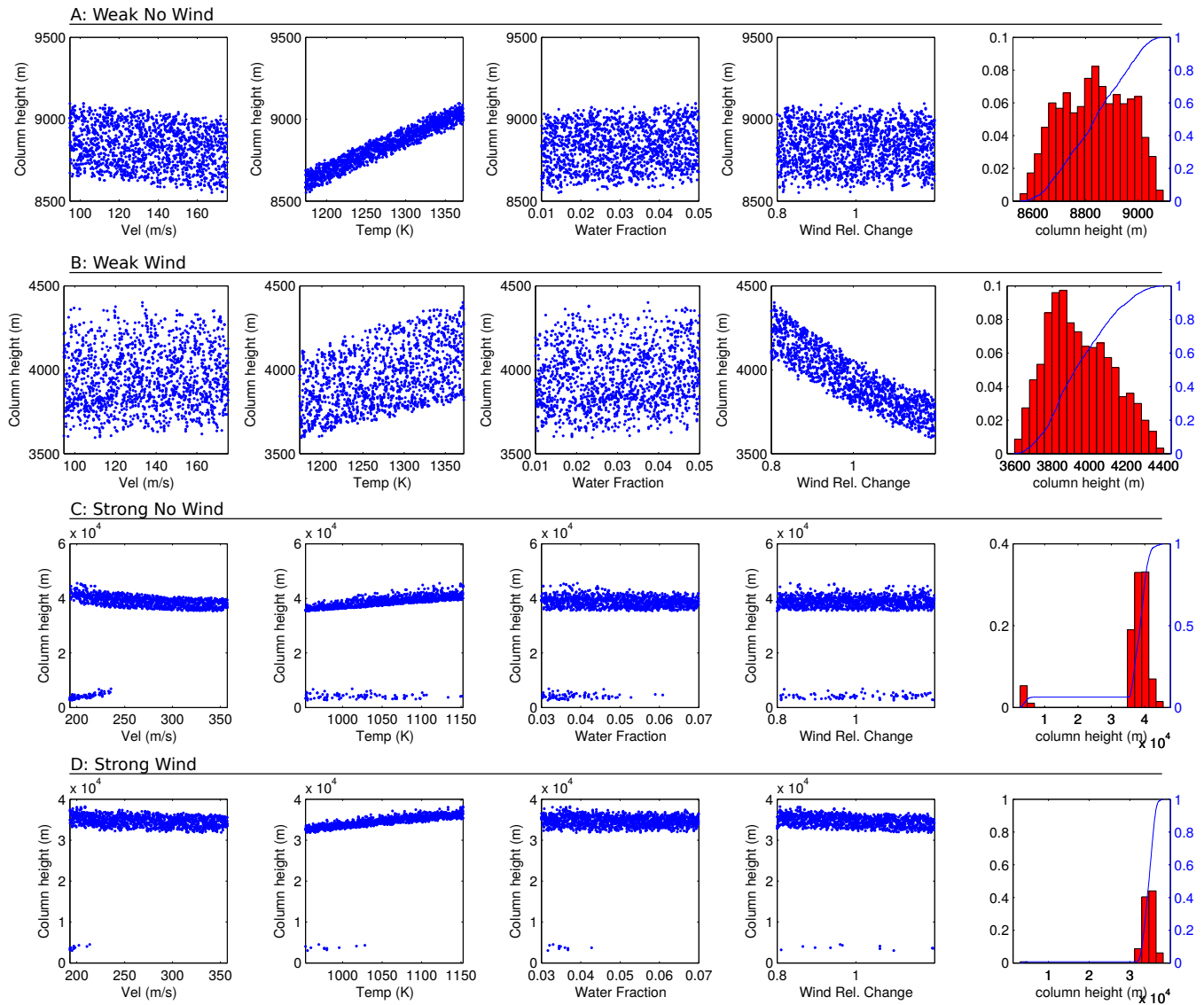

Figure 9: Variation in maximum plume height (above the vent) with input parameters for the weak and strong plume examples when mass flux is kept constant $(1.5 \mathrm{E}+05$ and $1.50 \mathrm{E}+09 \mathrm{~kg} / \mathrm{s}$ for the weak and strong plume respectively) changing the vent diameter. In the plots each marker represents a single simulation. The right hand column shows a histogram and cumulative density function of the resultant modelled plume heights. 


\section{References}

Adams, B. M., Dalbey, K. R., Eldred, M. S., Swiler, L. P., Bohnhoff, W. J., Eddy, J. P., Vigil, D. M., Hough, P. D., Lefantzi, S., 2011. DAKOTA, A Multilevel Parallel Object-Oriented Framework for Design Optimization, Parameter Estimation, Uncertainty Quantification, and Sensitivity Analysis: Version 5.2 Uers's Manual.

Arason, P., Petersen, G., Bjornsson, H., 2011. Observations of the altitude of the volcanic plume during the eruption of Eyjafjallajökull, April-May 2010. Earth System Science Data 3 (1), 9-17.

Barsotti, S., Andronico, D., Neri, A., Del Carlo, P., Baxter, P., Aspinall, W., Hincks, T., 2010. Quantitative assessment of volcanic ash hazards for health and infrastructure at Mt. Etna (Italy) by numerical simulation. Journal of Volcanology and Geothermal Research 192 (1), 85-96.

Barsotti, S., Neri, A., 2008. The VOL-CALPUFF model for atmospheric ash dispersal: 2. Application to the weak Mount Etna plume of July 2001. Journal of Geophysical Research: Solid Earth (1978-2012) 113 (B3).

Barsotti, S., Neri, A., Scire, J., 2008. The VOL-CALPUFF model for atmospheric ash dispersal: 1. Approach and physical formulation. Journal of Geophysical Research 113 (B3208).

Bonadonna, C., Costa, A., Folch, A., Koyaguchi, T., 2015. Tephra Dispersal and Sedimentation. In: Sigurdsson, H. (Ed.), Encyclopedia of Volcanoes, 2nd Edition. Academic Press, Ch. 33, pp. 587-597.

Bursik, M., 2001. Effect of wind on the rise height of volcanic plumes. Geophysical Research Letters 18, 3621-3624.

Bursik, M. I., Woods, A. W., 1991. Buoyant, superbuoyant and collapsing eruption columns. Journal of Volcanology and Geothermal Research 45 (3), $347-350$.

Carazzo, G., Kaminski, E., Tait, S., 2008. On the dynamics of volcanic columns: A comparison of field data with a new model of negatively buoyant jets. Journal of Volcanology and Geothermal Research 178 (1), 94-103.

Carey, S., Bursik, M., 2015. Volcanic Plumes. In: Sigurdsson, H. (Ed.), Encyclopedia of Volcanoes, 2nd Edition. Academic Press, Ch. 32, pp. 571-585. 
Colucci, S., de' Michieli Vitturi, M., Neri, A., Palladino, D. M., 2014. An integrated model of magma chamber, conduit and column for the analysis of sustained explosive eruptions. Earth and Planetary Science Letters 404, 98-110.

Costa, A., Folch, A., Macedonio, G., 2013. Density-driven transport in the umbrella region of volcanic clouds: Implications for tephra dispersion models. Geophysical Research Letters 40 (18), 4823-4827.

Costa, A., Suzuki, Y. J., Cerminara, M., Devenish, B. J., Esposti Ongaro, T., Herzon, M., Van Eaton, A. R., Denby, L. C., Bursik, M., de' Michieli Vitturi, M., Engwell, S., Neri, B., Barsotti, S., Folch, A., Macedonio, G., Girault, F., Carazzo, G., Tait, S., Kaminski, E., Mastin, L. G., Woodhouse, M. J., Phillips, J. C., Hogg, A. J., Degruyter, W., Bonadonna, C., this issue. Results of the eruption column model inter-comparison study. Journal of Volcanology and Geothermal Research.

de' Michieli Vitturi, M., Neri, A., Barsotti, S., 2015. PLUME-MoM 1.0: A new integral model of volcanic plumes based on the method of moments. Geoscientific Model Development 8 (8), 2447-2463.

Degruyter, W., Bonadonna, C., 2012. Improving on mass flow rate estimates of volcanic eruptions. Geophysical Research Letters 39 (16).

Degruyter, W., Bonadonna, C., 2013. Impact of wind on the condition for column collapse of volcanic plumes. Earth and Planetary Science Letters $377,218-226$.

Devenish, B. J., Rooney, G. G., Webster, H. N., Thomson, D. J., 2010. The entrainment rate of buoyant plumes in a crossflow. Boundary Layer Meteorology, 134, 411-439.

Devenish, B. J., 2013. Using simple plume models to refine the source mass flux of volcanic eruptions according to atmospheric conditions. Journal of Volcanology and Geothermal Research 256, 118-127.

Durant, A. J., Bonadonna, C., Horwell, C. J., 2010. Atmospheric and environmental impacts of volcanic particulates. Elements 6 (4), 235-240.

Engwell, S. L., Barsotti, S., de' Michieli Vitturi, M., Neri, A., 2014. Multiparametric Study of Wind and Atmosphere Effect on Explosive Eruptive 
Style. In: AGU (Editor), Abstract V53E-04 presented at 2014 AGU Fall Meeting, San Francisco, Calif.

Folch, A., Costa, A., Macedonio, G., 2015. FPLUME-1.0: an integral volcanic plume model accounting for ash aggregation. Geoscientific Model Development 9, 1-20.

Hashimoto, A., Shimbori, T., Fukui, K., 2012. Tephra fall simulation for the eruptions at Mt. Shinmoe-dake during 26-27 January 2011 with JMANHM. Sola $8(0), 37-40$.

Hewett, T. A., Fay, J. A., Hoult, D. P., 1971. Laboratory experiments of smokestack plumes in a stable atmosphere. Atmospheric Environment, 5, 769-789.

Holasek, R., Self, S., Woods, A., 1996. Satellite observations and interpretation of the 1991 Mount Pinatubo eruption plumes. Journal of Geophysical Research: Solid Earth (1978-2012) 101 (B12), 27635-27655.

Iman, R. L., Davenport, J. M., Zeigler, D. K., 1980. Latin hypercube sampling (program user's guide).[LHC, in FORTRAN]. Tech. rep., Sandia Labs., Albuquerque, NM (USA).

Iman, R. L., Helton, J. C., 1988. An investigation of uncertainty and sensitivity analysis techniques for computer models. Risk analysis 8 (1), 71-90.

Kaminski, E., Tait, S., Carazzo, G., 2005. Turbulent entrainment in jets with arbitrary buoyancy. Journal of Fluid Mechanics 526, 361-376.

Koyaguchi, T., Suzuki, Y. J., Kozono, T., 2010. Effects of the crater on eruption column dynamics. Journal of Geophysical Research: Solid Earth, 115, B07205.

Koyaguchi, T., Woods, A. W., 1996. On the formation of eruption columns following explosive mixing of magma and surface water. Journal of Geophysical Research: Solid Earth, 101, B3, 5561-5574.

Kozono, T., Ueda, H., Ozawa, T., Koyaguchi, T., Fujita, E., Tomiya, A., Suzuki, Y. J., 2013. Magma discharge variations during the 2011 eruptions of Shinmoe-dake volcano, Japan, revealed by geodetic and satellite observations. Bulletin of volcanology 75 (3), 1-13. 
Marchisio, D. L., Fox, R. O., 2013. Computational Models for Polydisperse Particulate and Multiphase Systems. Cambridge University Press.

Mastin, L., Guffanti, M., Servranckx, R., Webley, P., Barsotti, S., Dean, K., Durant, A., Ewert, J., Neri, A., Rose, W., et al., 2009. A multidisciplinary effort to assign realistic source parameters to models of volcanic ash-cloud transport and dispersion during eruptions. Journal of Volcanology and Geothermal Research 186 (1), 10-21.

Mastin, L.G., 2014. Testing the accuracy of a 1-D volcanic plume model in estimating mass eruption rate. Journal of Geophysical Research: Atmospheres 119, 2474-2495.

Morton, B., Taylor, G., Turner, J., 1956. Turbulent gravitational convection from maintained and instantaneous sources. In: Proceedings of the Royal Society of London A: Mathematical, Physical and Engineering Sciences. Vol. 234. The Royal Society, pp. 1-23.

Pfeiffer, T., Costa, A., Macedonio, G., 2005. A model for the numerical simulation of tephra fall deposits. Journal of Volcanology and Geothermal Research 140 (4), 273-294.

Rougier, J., Sparks, S., Hill, L. J., 2013. Risk and Uncertainty Assessment for Natural Hazards. Cambridge University Press.

Saltelli, A., Annoni, P., Azzini, I., Campolongo, F., Ratto, M., Tarantola, S., 2010. Variance based sensitivity analysis of model output. Design and estimator for the total sensitivity index. Computer Physics Communications $181(2), 259-270$.

Scollo, S., Tarantola, S., Bonadonna, C., Coltelli, M., Saltelli, A., 2008. Sensitivity analysis and uncertainty estimation for tephra dispersal models. Journal of Geophysical Research-Solid Earth 113 (B6), 1-17.

Settle, M., 1978. Volcanic eruption clouds and the thermal power output of explosive eruptions. Journal of Volcanology and Geothermal Research 3 (3), 309-324.

Shimbori, T., Fukui, K., 2012. Time variation of the eruption cloud echo height from Shinmoe-dake volcano in 2011 observed by Tanegashima and 
Fukuoka weather radars: Part II. Rep. Coordinating comm. for Prediction of Volcanic Eruption 109.

Sparks, R., 1986. The dimensions and dynamics of volcanic eruption columns. Bulletin of Volcanology 48 (1), 3-15.

Sparks, R. S. J., Bursik, M. I., Carey, S. N., Gilbert, J. E., Glaze, L., Sigurdsson, H., Woods, A. W., 1997. Volcanic plumes. John Wiley \& Sons Inc.

Spinetti, C., Barsotti, S., Neri, A., Buongiorno, M., Doumaz, F., Nannipieri, L., 2013. Investigation of the complex dynamics and structure of the 2010 Eyjafjallajökull volcanic ash cloud using multispectral images and numerical simulations. Journal of Geophysical Research: Atmospheres 118 (10), 4729-4747.

Suzuki, Y. J., Koyaguchi, T., 2010. Numerical determination of the efficiency of entrainment in volcanic eruption columns. Geophysical Research Letters 37, L05302.

Suzuki, Y. J. ,Costa, A., Cerminara, M., Esposti Ongaro, T., Herzog, M., Van Eaton, A. R., Denby, L. C., 2016. Inter-comparison of three-dimensional models of volcanic plumes. Journal of Volcanology and Geothermal Research.

Suzuki, Y. J., Koyaguchi, T., 2013. 3D numerical simulation of volcanic eruption clouds during the 2011 Shinmoe-dake eruptions. Earth, Planets and Space 65 (6), 581-589.

Suzuki, Y. J., Koyaguchi, T., 2015. Effects of wind on entrainment efficiency in volcanic plumes. Journal of Geophysical Research: Solid Earth 120, 6122-6140.

Textor, C., Graf, H. F., Herzog, M., Oberhuber, J. M., Rose, W. I., Ernst, G. G. J., 2006. Volcanic particle aggregation in explosive eruption columns. Part I: Parameterization of the microphysics of hydrometeors and ash. Journal of Volcanology and Geothermal Research 150, 359-377.

Wilson, G., Wilson, T., Deligne, N., Cole, J., 2014. Volcanic hazard impacts to critical infrastructure: A review. Journal of Volcanology and Geothermal Research 286, 148-182. 
934

Woodhouse, M., Hogg, A., Phillips, J., Sparks, R., 2013. Interaction between volcanic plumes and wind during the 2010 Eyjafjallajökull eruption, Iceland. Journal of Geophysical Research: Solid Earth 118 (1), 92-109.

Woodhouse, M. J., Hogg, A. J., Phillips, J. C., Rougier, J. C., 2015. Uncertainty analysis of a model of wind-blown volcanic plumes. Bullettin of Volcanology 77 (10), 1-28.

Woods, A. W., 1988. The fluid dynamics and thermodynamics of eruption columns. Bulletin of Volcanology 50, 169-193. 


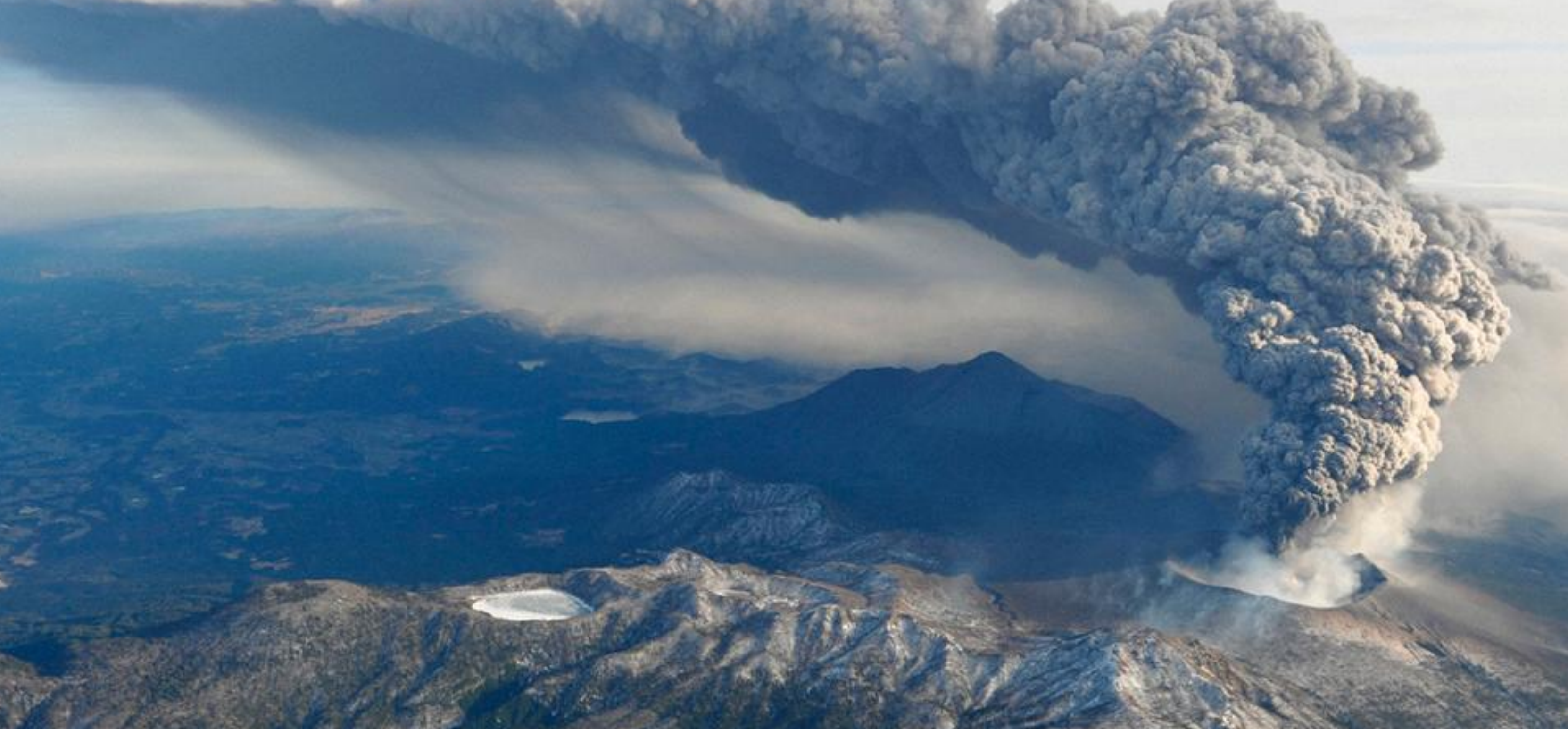

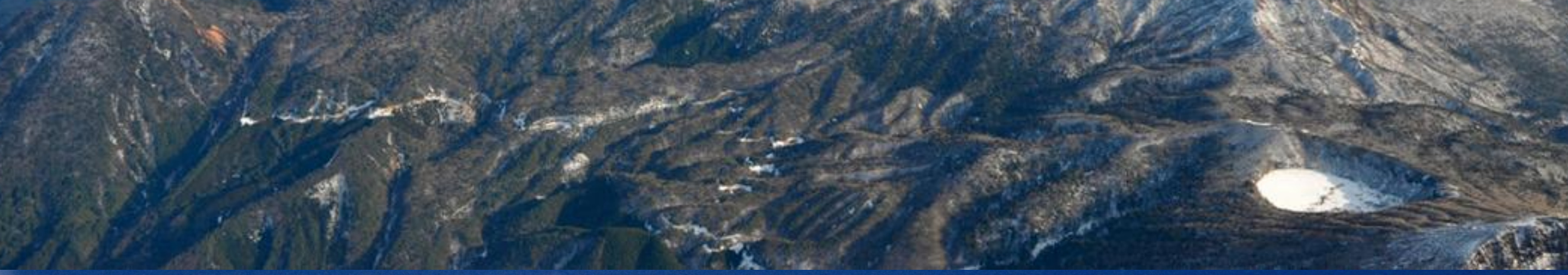

B.

.

.

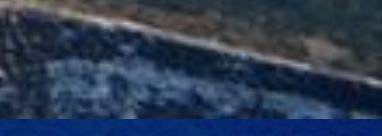

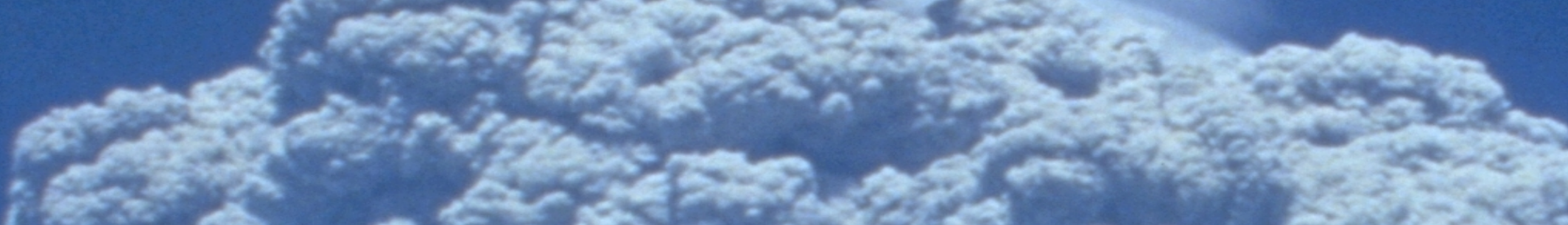

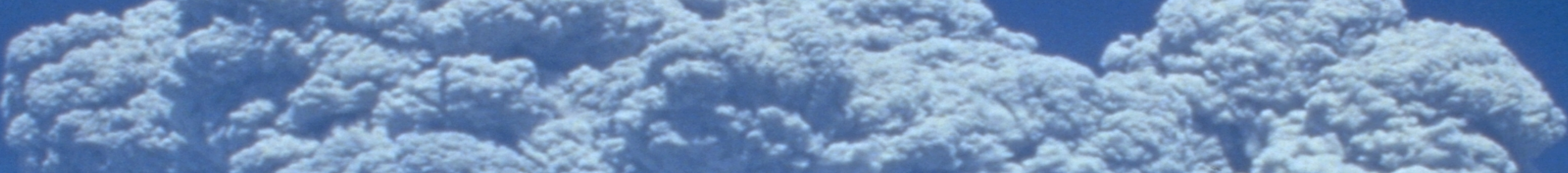

iscosises?

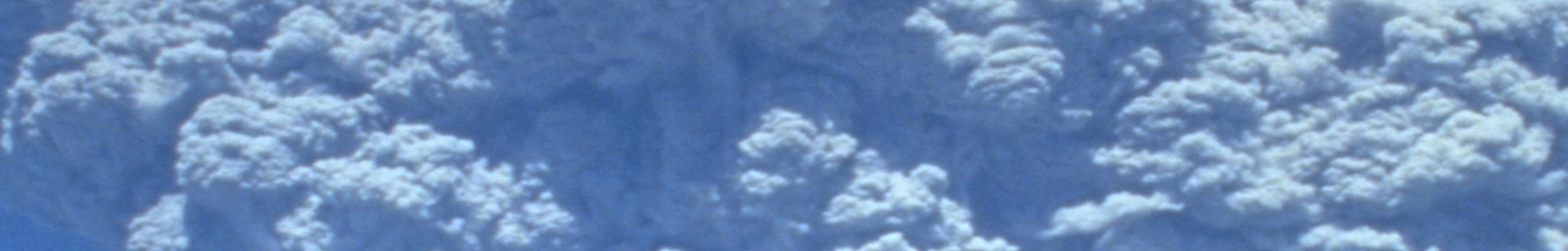

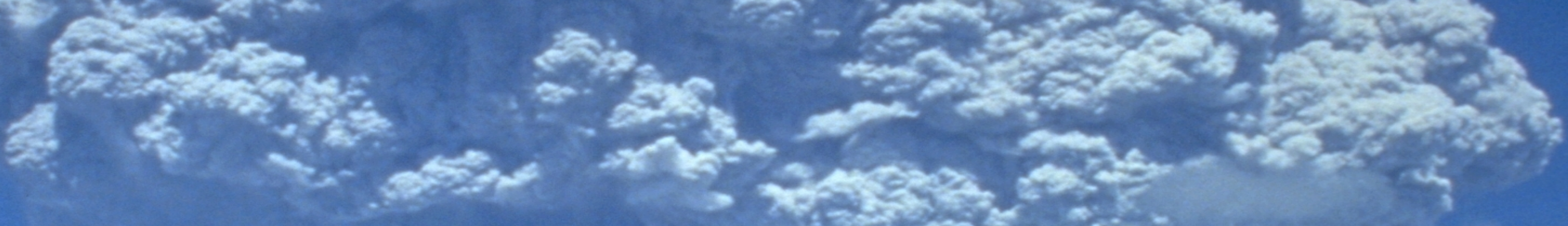

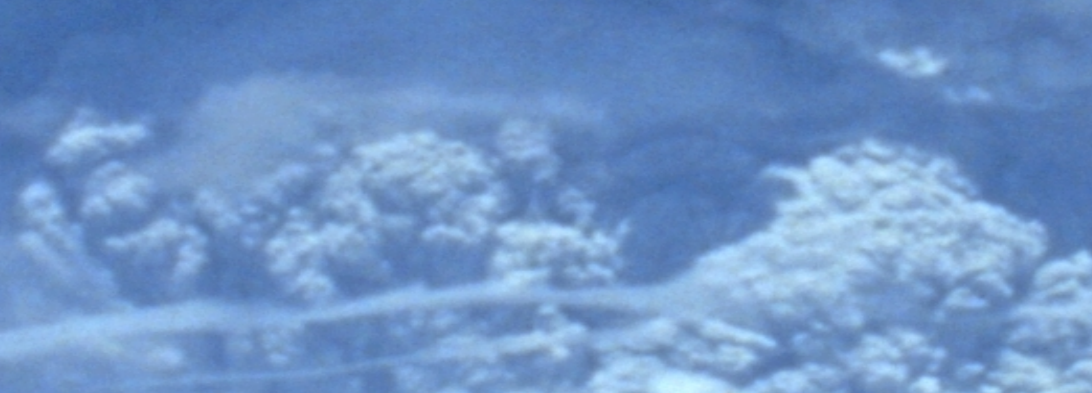

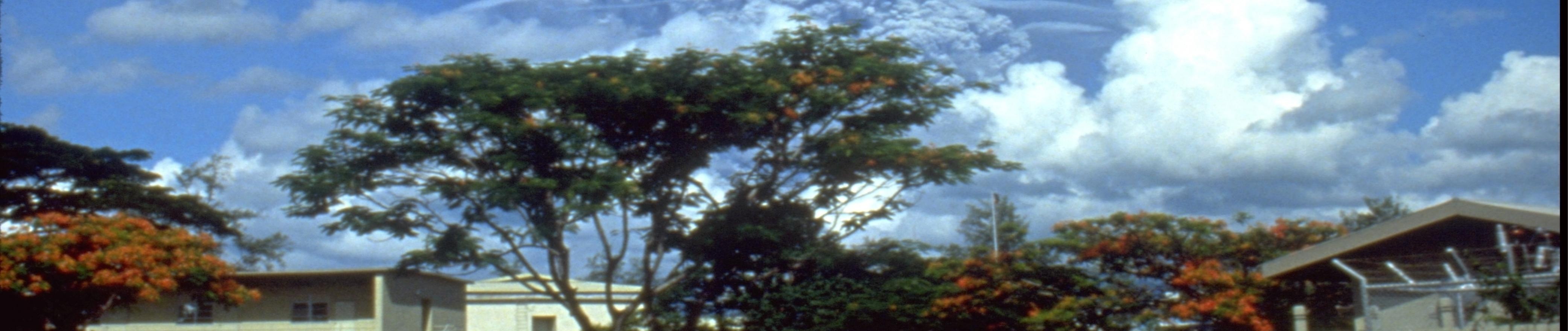




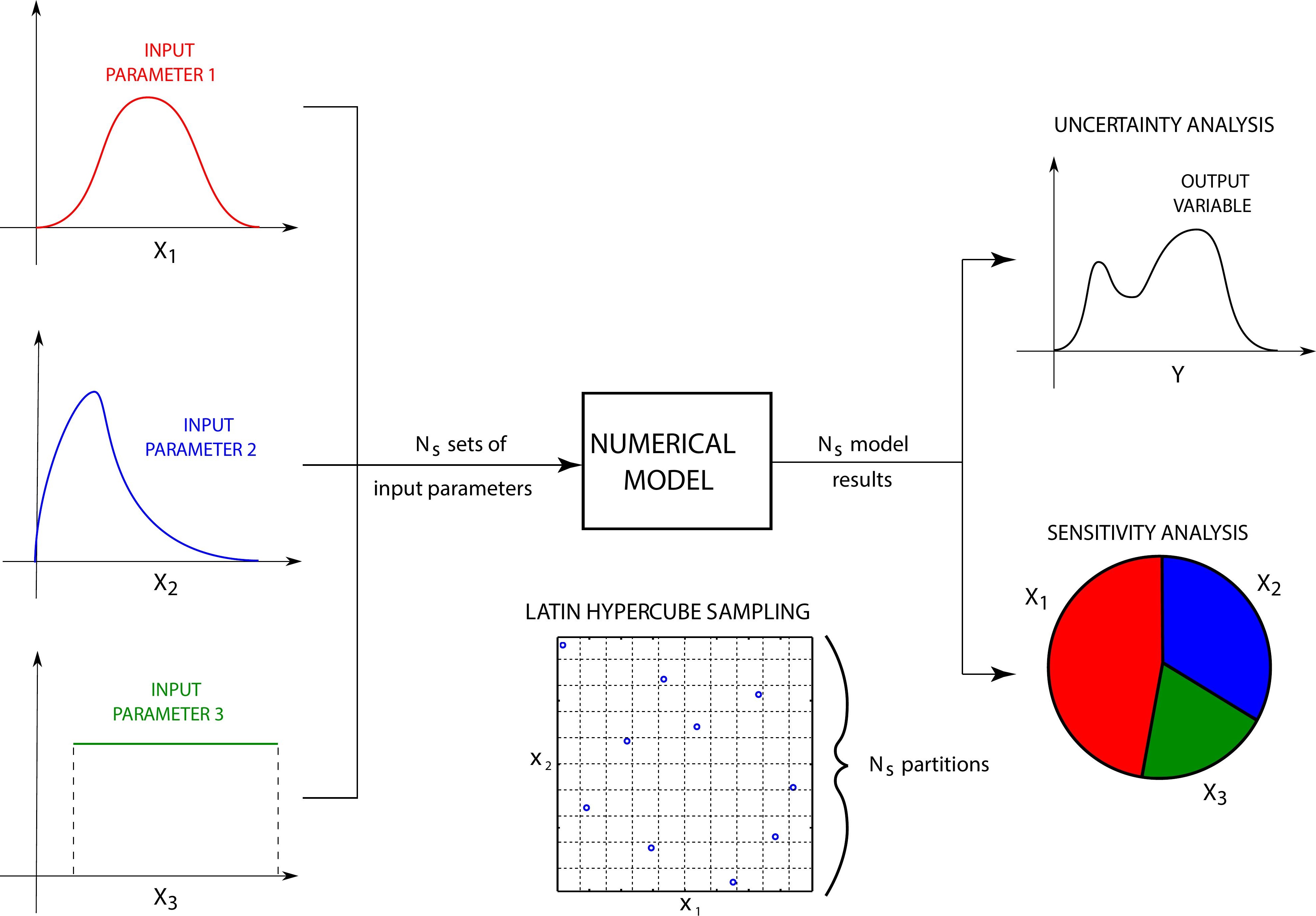




\section{Weak plume}

A.

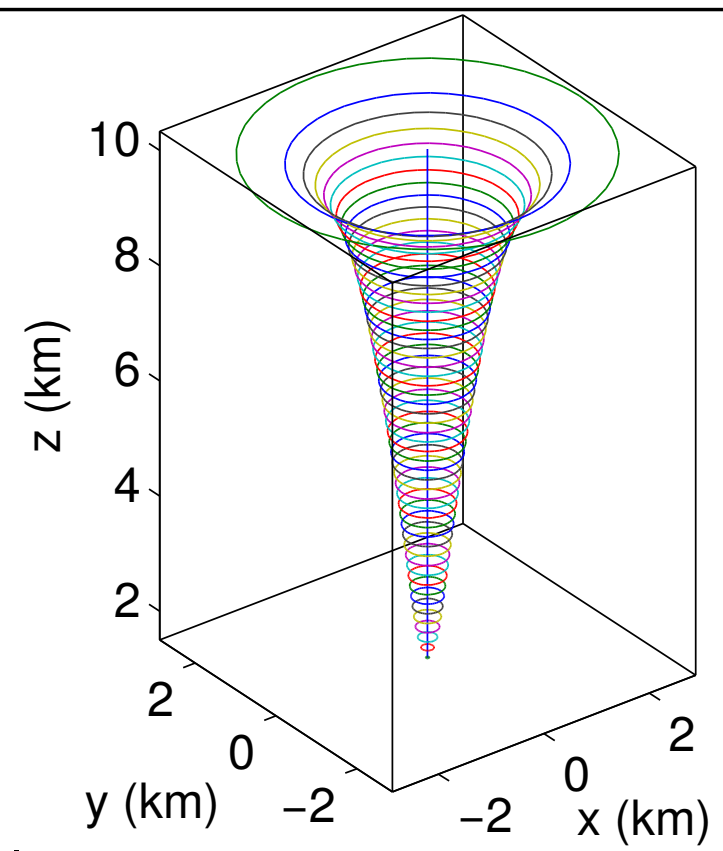

Strong plume

B.

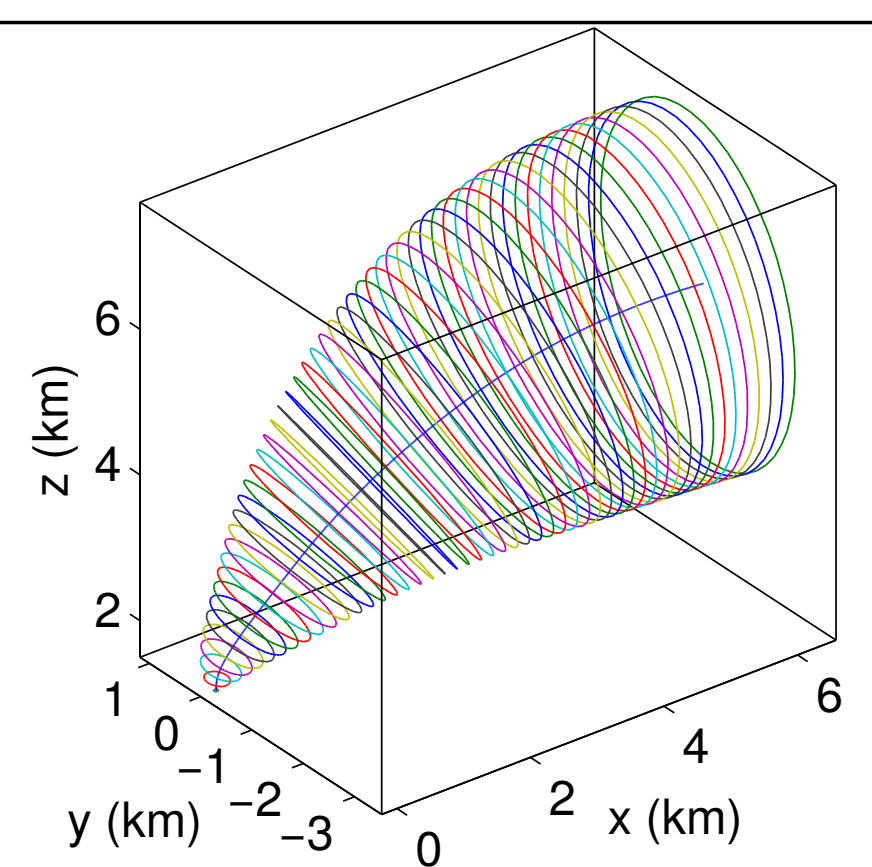

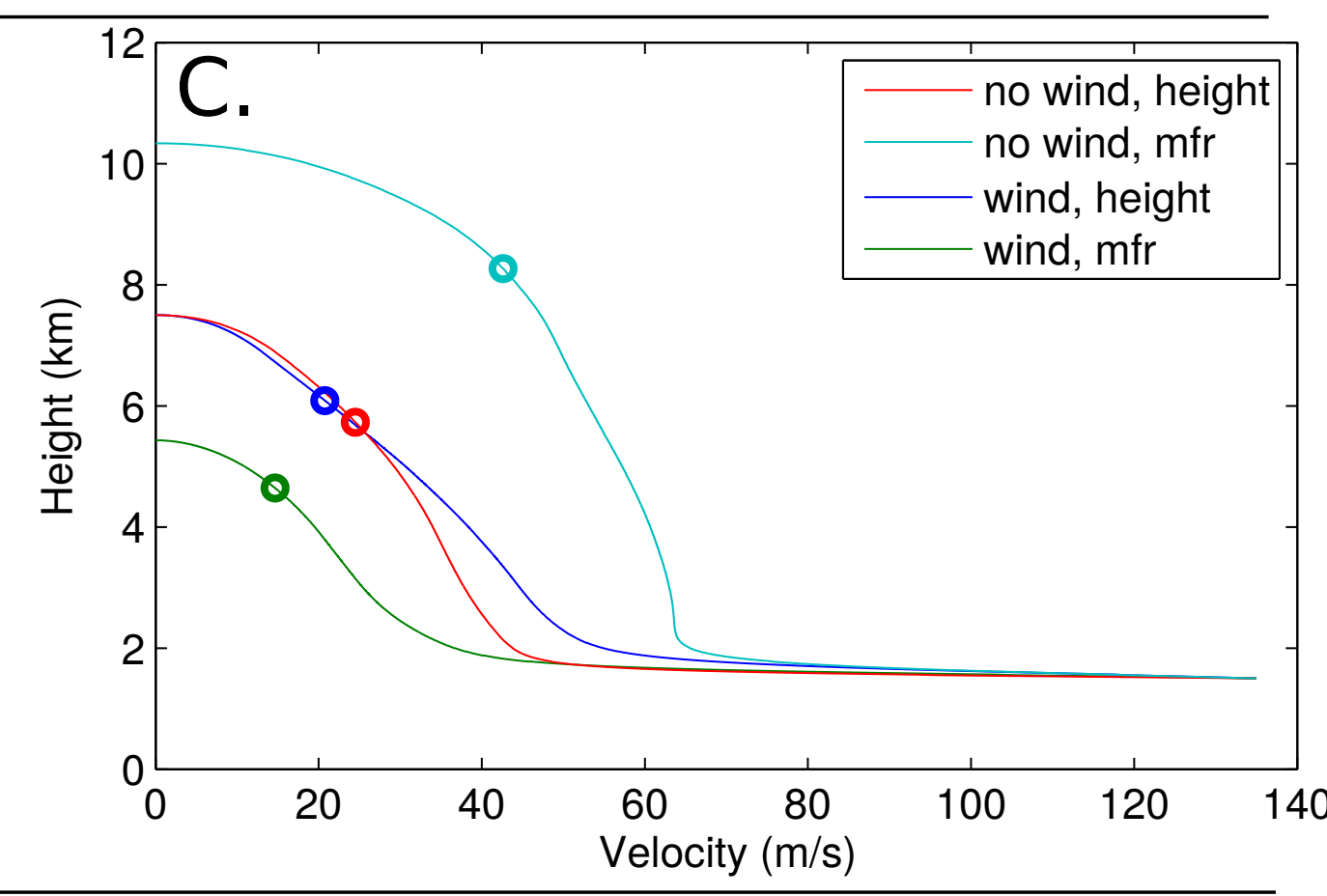
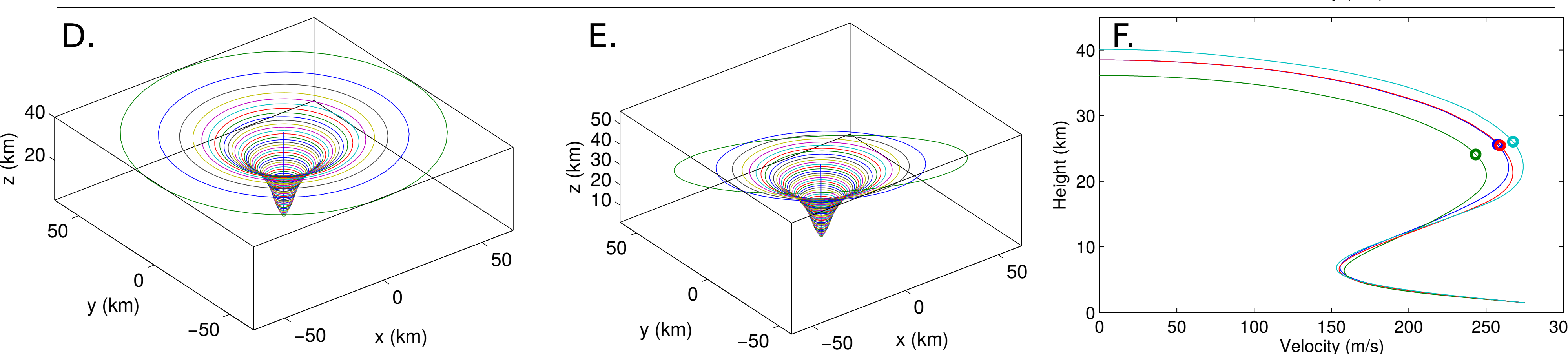


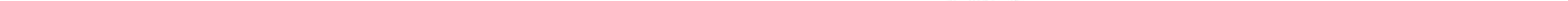




\section{A: Weak plume, no wind}
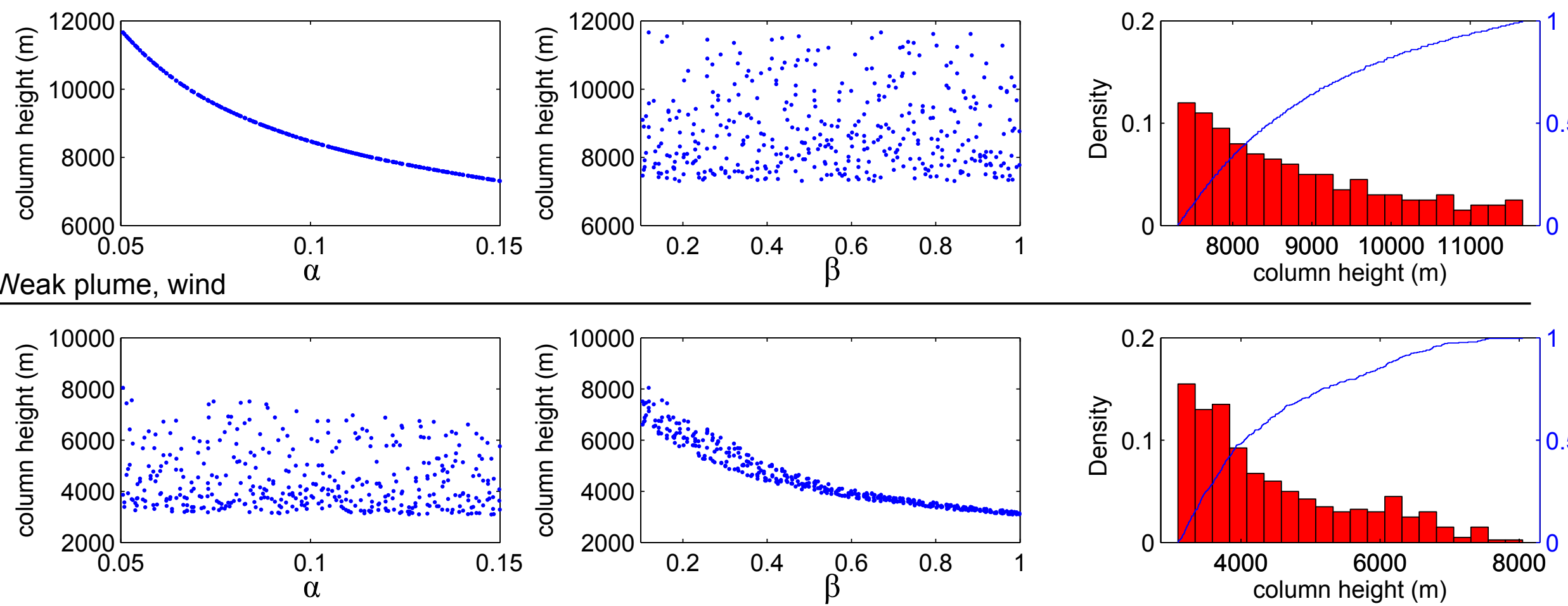

C: Strong plume, no wind
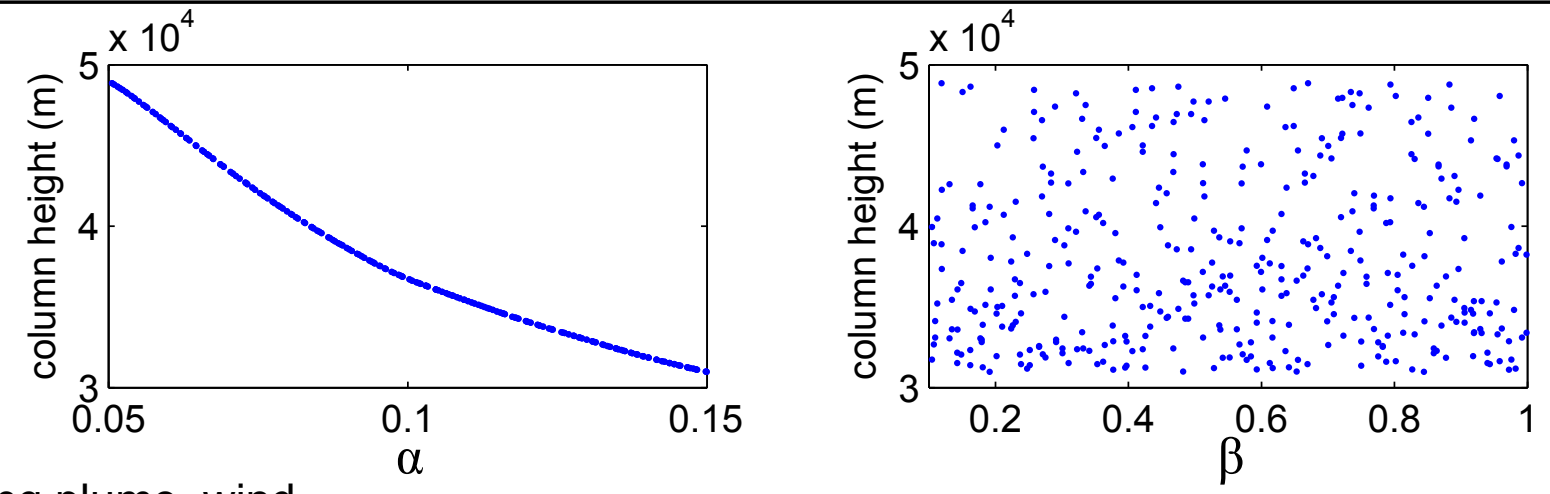

D: Strong plume, wind
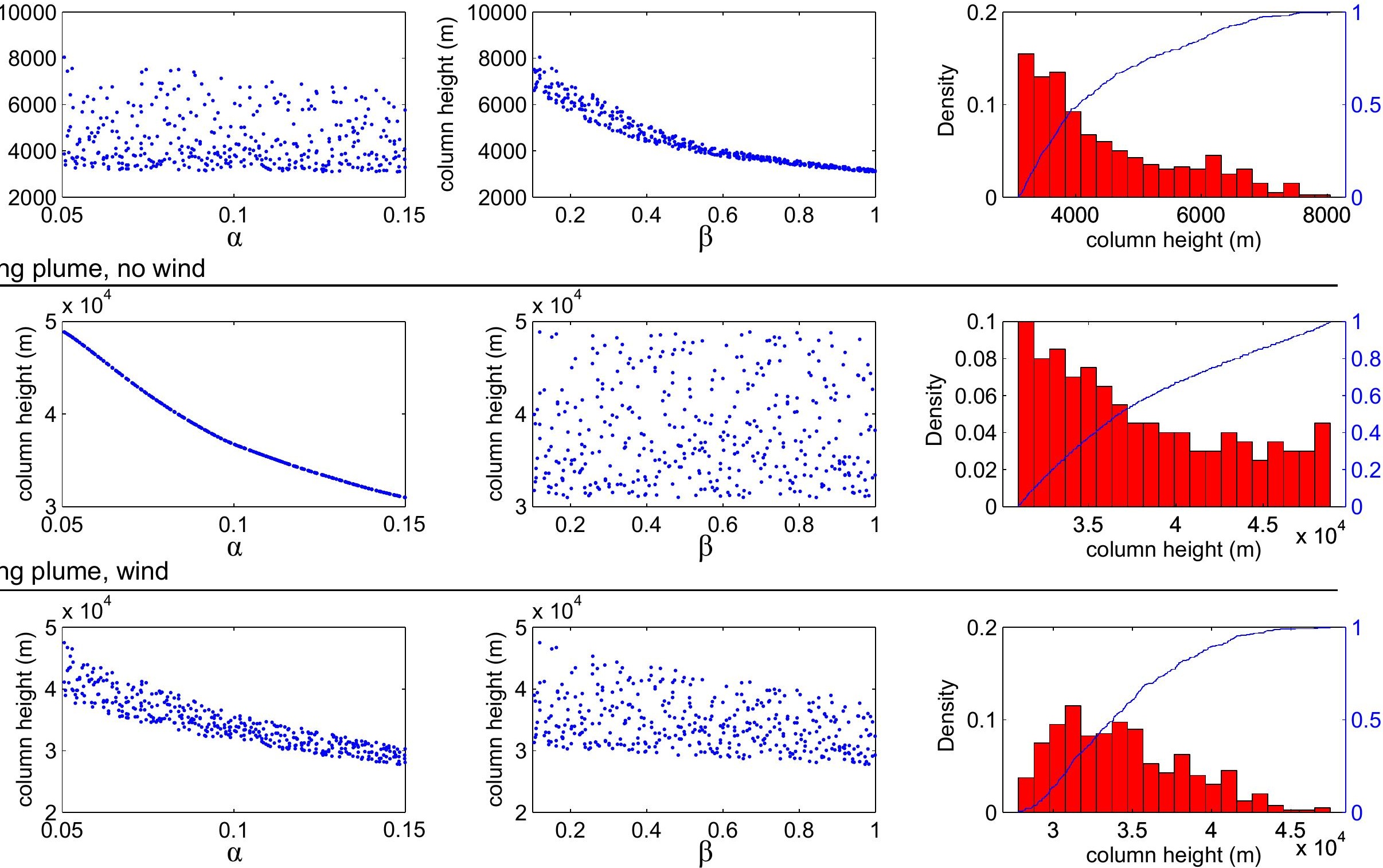

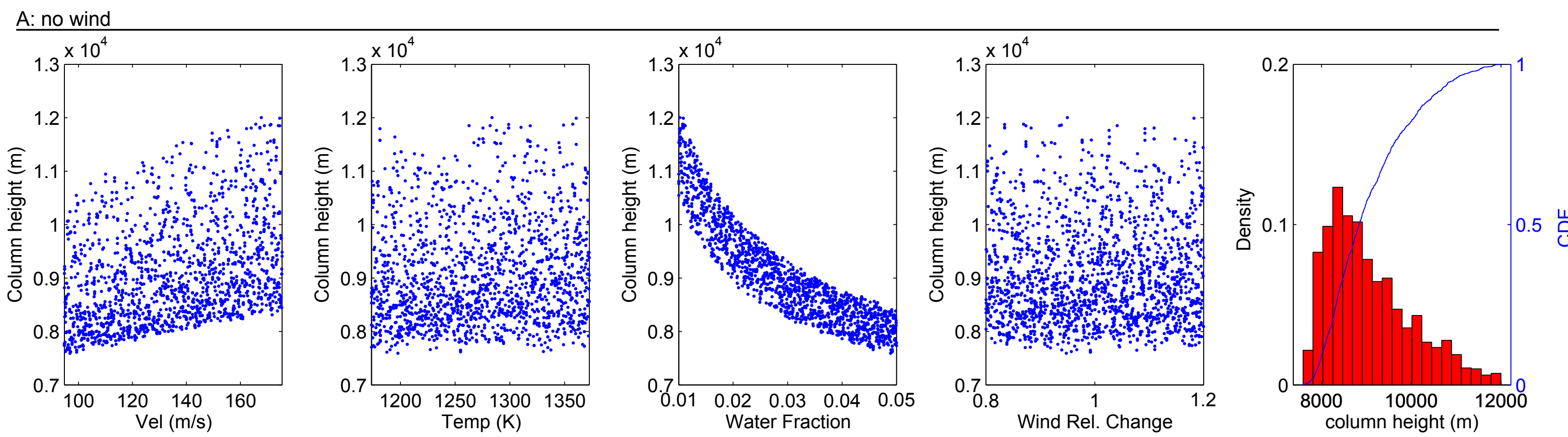

\section{B: Wind}
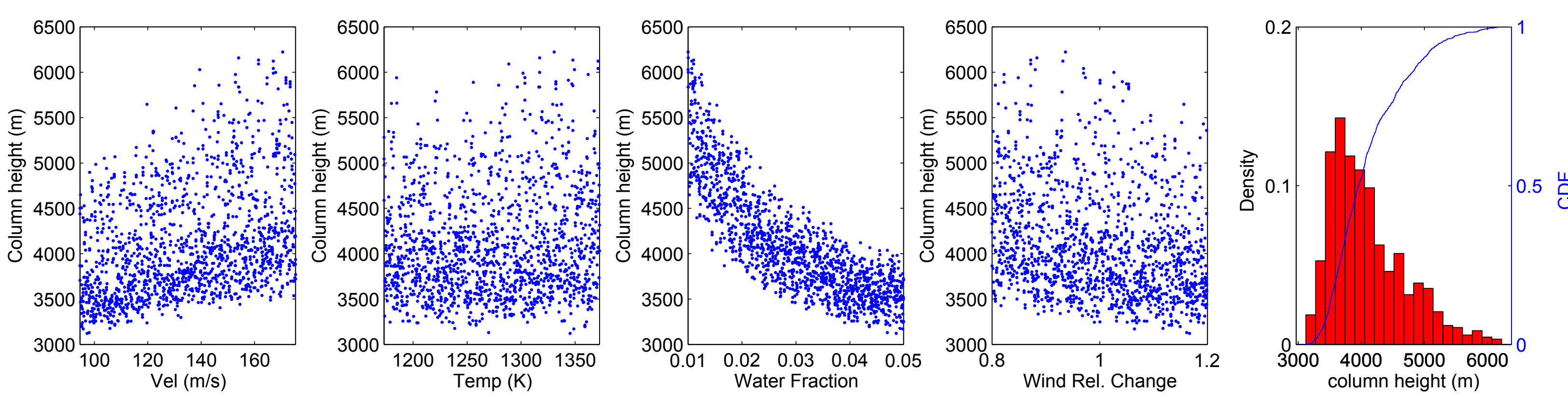

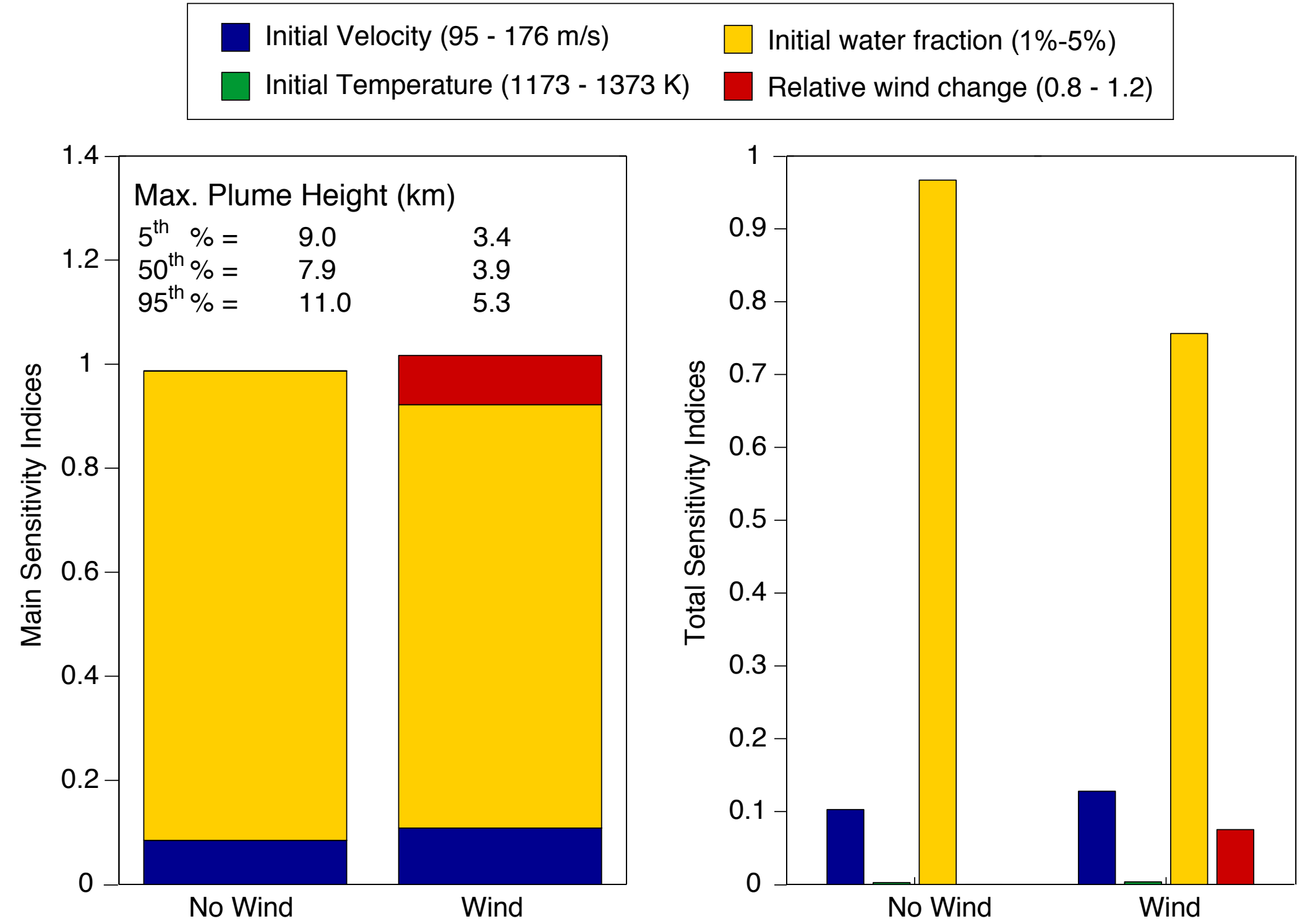


\section{A: No wind}
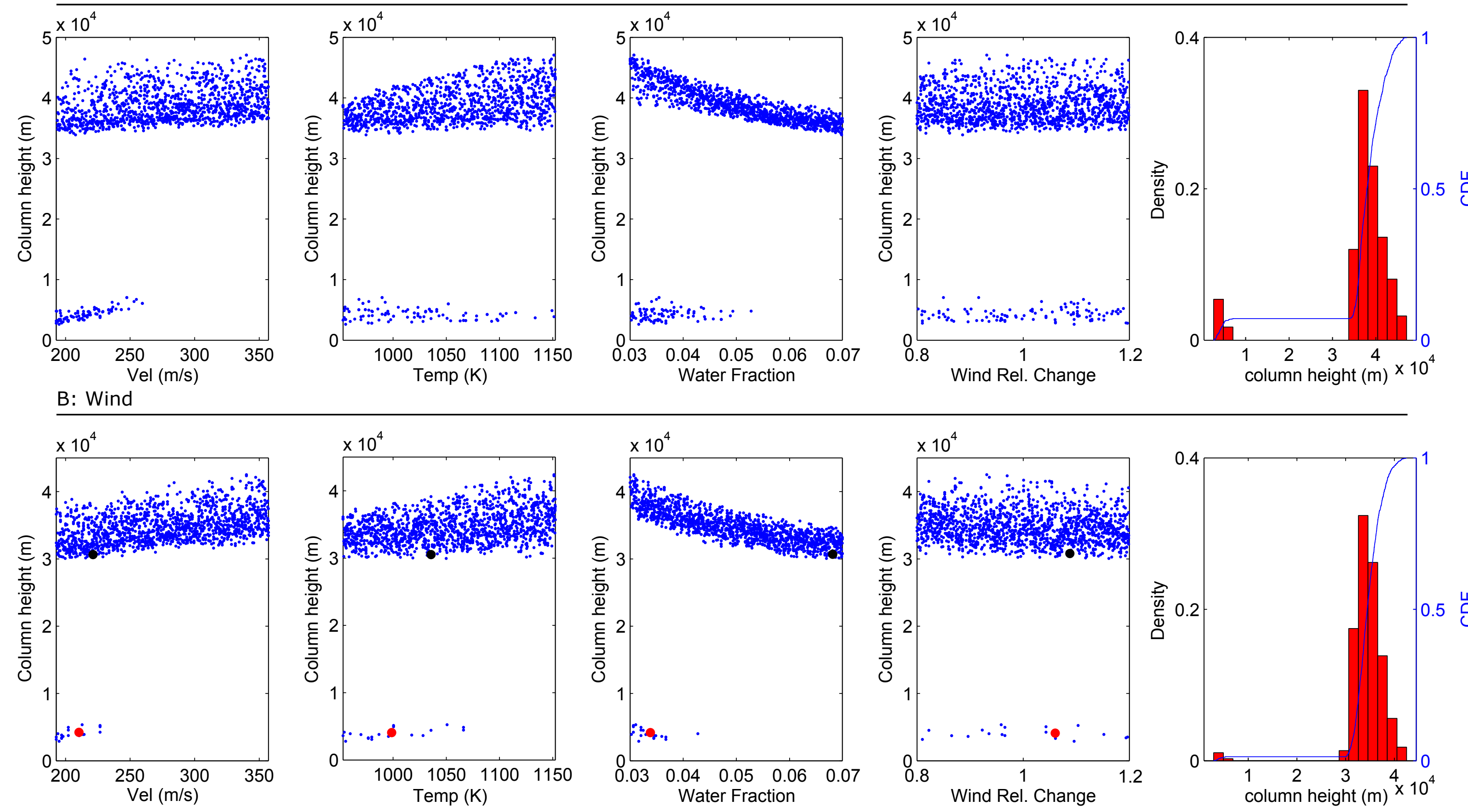

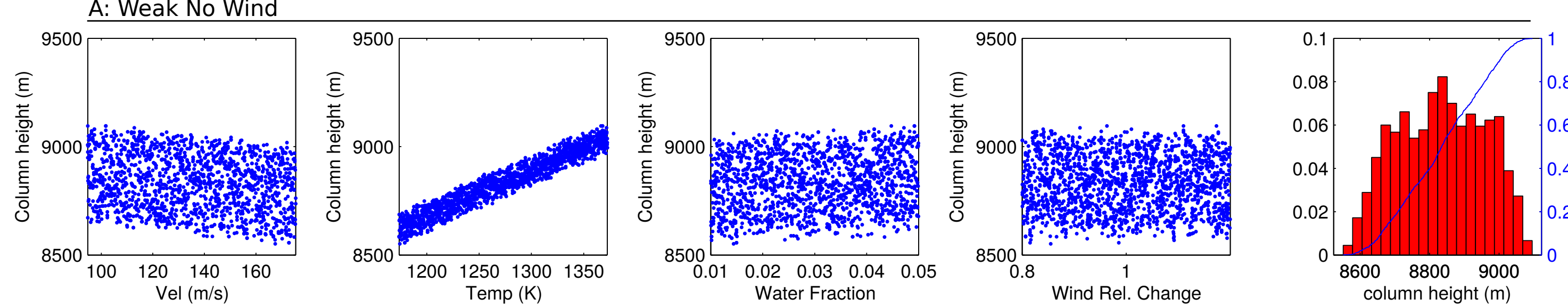

B: Weak Wind
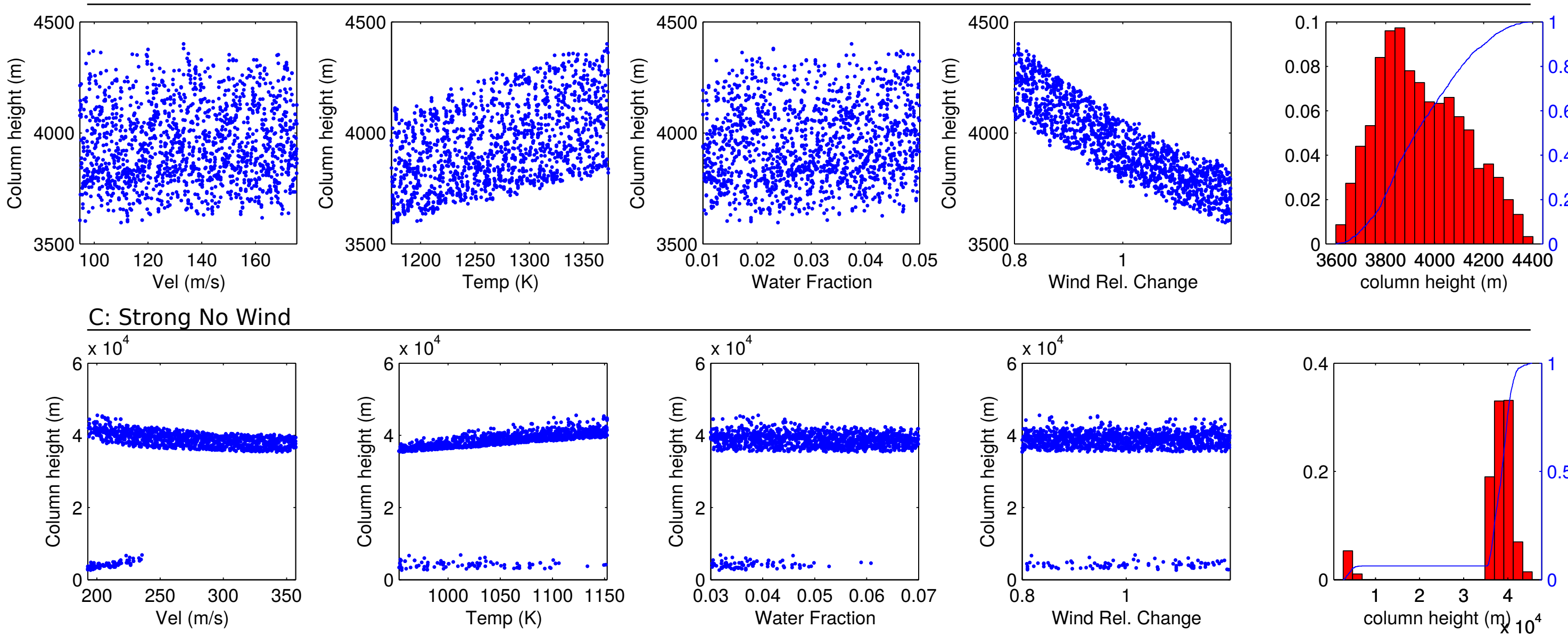

D: Strong Wind
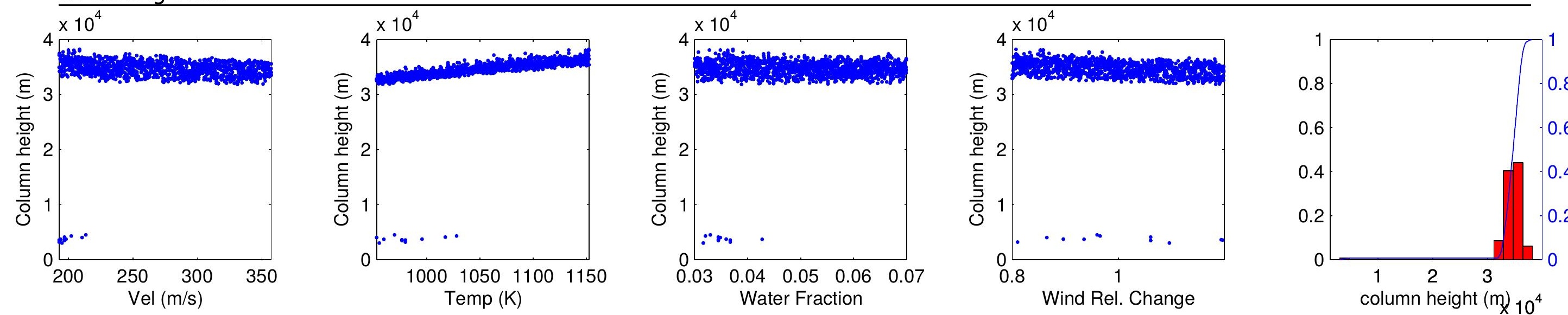